\title{
Seismic imaging of slab metamorphism and genesis of intermediate-depth intraslab earthquakes
}

\author{
Akira Hasegawa ${ }^{{ }^{*}}$ (D) and Junichi Nakajima ${ }^{2}$
}

\begin{abstract}
We review studies of intermediate-depth seismicity and seismic imaging of the interior of subducting slabs in relation to slab metamorphism and their implications for the genesis of intermediate-depth earthquakes. Intermediate-depth events form a double seismic zone in the depth range of c. 40-180 km, which occur only at locations where hydrous minerals are present, and are particularly concentrated along dehydration reaction boundaries. Recent studies have revealed detailed spatial distributions of these events and a close relationship with slab metamorphism. Pressure-temperature paths of the crust for cold slabs encounter facies boundaries with large $\mathrm{H}_{2} \mathrm{O}$ production rates and positive total volume change, which are expected to cause highly active seismicity near the facies boundaries. A belt of upper-plane seismicity in the crust nearly parallel to 80-90 km depth contours of the slab surface has been detected in the cold Pacific slab beneath eastern Japan, and is probably caused by slab crust dehydration with a large $\mathrm{H}_{2} \mathrm{O}$ production rate. A seismic low-velocity layer in the slab crust persists down to the depth of this upper-plane seismic belt, which provides evidence for phase transformation of dehydration at this depth. Similar low-velocity subducting crust closely related with intraslab seismicity has been detected in several other subduction zones. Seismic tomography studies in NE Japan and northern Chile also revealed the presence of a P-wave low-velocity layer along the lower plane of a double seismic zone. However, in contrast to predictions based on the serpentinized mantle, S-wave velocity along this layer is not low. Seismic anisotropy and pore aspect ratio may play a role in generating this unique structure. Although further validation is required, observations of these distinct low P-wave velocities along the lower seismic plane suggest the presence of hydrated rocks or fluids within that layer. These observations support the hypothesis that dehydration-derived $\mathrm{H}_{2} \mathrm{O}$ causes intermediate-depth intraslab earthquakes. However, it is possible that dual mechanisms generate these earthquakes; the initiation of earthquake rupture may be caused by local excess pore pressure from $\mathrm{H}_{2} \mathrm{O}$, and subsequent ruptures may propagate through thermal shear instability. In either case, slab-derived $\mathrm{H}_{2} \mathrm{O}$ plays an important role in generating intermediate-depth events.
\end{abstract}

Keywords: Internal slab structure, Slab metamorphism, Dehydration-related embrittlement, Intermediate-depth earthquake, Intraslab earthquake, Earthquake generation mechanism, Subduction zone

\section{Introduction}

Subduction of oceanic lithosphere causes high seismic activity in subduction zones. The shallow portion of the plate interface between a subducting oceanic plate and an overriding continental plate is locked by friction. To release the stress that accumulates from this interplate

\footnotetext{
* Correspondence: akira.hasegawa.d8@tohoku.ac.jp

${ }^{1}$ Research Center for Prediction of Earthquakes and Volcanic Eruptions, Graduate School of Science, Tohoku University, Aramaki, Aoba-ku, Sendai 980-8578, Japan

Full list of author information is available at the end of the article
}

locking, the locked portion of the plate interface occasionally slips dynamically and causes interplate earthquakes. Plate convergence at subduction zones also causes stress accumulation within both the overriding continental lithosphere and the subducting oceanic lithosphere. To release this accumulated stress, earthquakes take place both in the overriding and subducting plates. Earthquakes that occur in a subducting plate are called intraslab earthquakes because the subducting oceanic lithosphere is referred to as the slab. Intraslab earthquakes can occur as deeply as the bottom of the 
upper mantle. With the exception of shallow events, all earthquakes occur within the subducting slab. Therefore, the maximum depth of earthquakes on Earth is c. $660 \mathrm{~km}$, or potentially slightly deeper. The global distribution of the focal depths of seismicity is bimodal (Fig. 1). The first, and largest, peak of earthquake frequency with depth occurs at very shallow depths between 0 and $30 \mathrm{~km}$. The frequency decreases almost exponentially to a depth of c. $300 \mathrm{~km}$, where a minimum emerges between c. 300 and $450 \mathrm{~km}$ in depth. The frequency then increases to a depth of c. $550 \mathrm{~km}$, where it reaches a local maximum of 550-600 km (Frohlich, 2006; Houston, 2007). Generally, intraslab earthquakes are divided into two groups based on focal depth. Events shallower than $300 \mathrm{~km}$ are defined as intermediatedepth earthquakes, and those deeper than $300 \mathrm{~km}$ are considered deep-focus earthquakes.

At the depths of intraslab earthquakes, lithostatic pressure, and therefore frictional strength, becomes too great to allow dynamic slips, i.e., earthquakes, along fault planes. In order to generate earthquakes at such great depths, shear stress must exceed that very large frictional strength. However, it is difficult to envision the application of such large shear stress on a fault where intermediate-depth and deep-focus events take place. Nevertheless, intermediate-

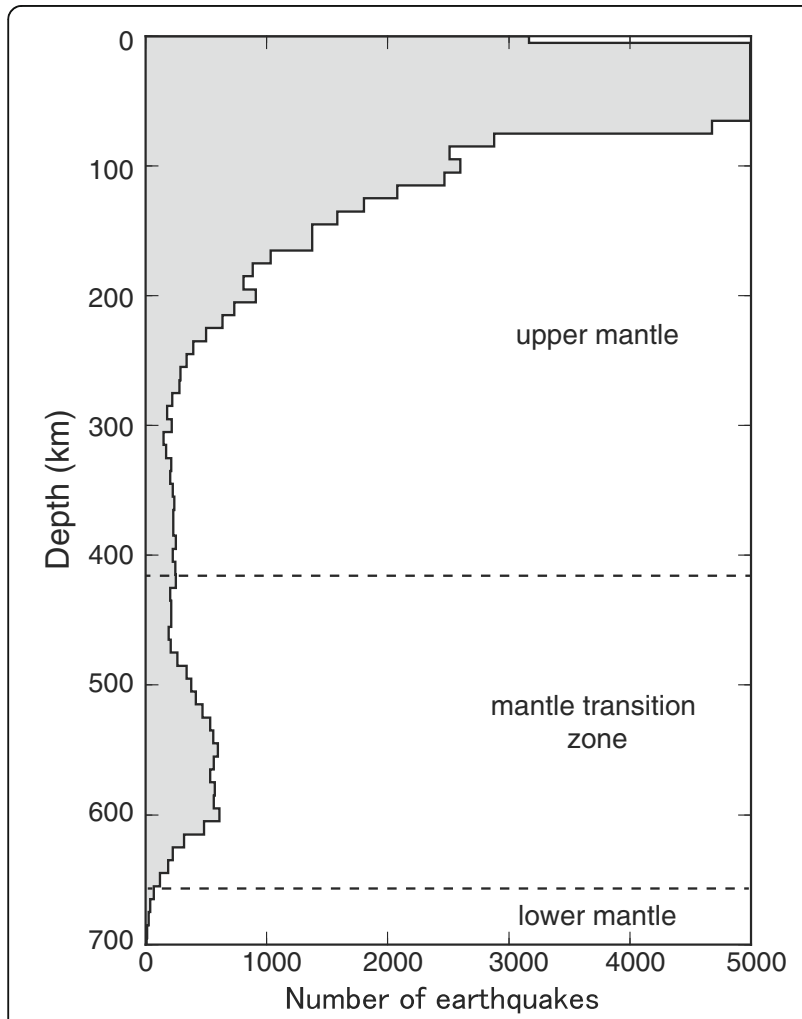

Fig. 1 Focal depth distribution of global seismicity for the period of 1960-2007. The shallower peak is truncated to show the deeper peak in detail depth and deep-focus earthquakes do occur in the subducting slab, and therefore the frictional strength must not be as high as expected. Therefore, some special mechanism must operate to lower the strength of friction and generate intermediate-depth and deep-focus intraslab earthquakes (e.g., Frohlich, 1994, 2006).

Although several plausible mechanisms have been proposed, the exact mechanism that generates intermediatedepth and deep-focus earthquakes remains unresolved. Some early studies explored the possibility that implosive phase change of mantle materials could cause intraslab earthquakes (e.g., Leith and Sharpe, 1936). However, subsequent studies have revealed that both intermediatedepth and deep-focus earthquakes generally do not have the large isotropic components that would be expected if this mechanism occurred (e.g., Hara et al. 1996; Kawakatsu, 1991, 1996; Kuge and Kawakatsu, 1993; Okal, 1996; Russakoff et al. 1997; Estabrook, 1999). Therefore, some other mechanism must exist to generate intraslab events. To date, leading hypotheses proposed to explain the occurrence of earthquakes at such great depths include thermal shear instability of plastic deformation (e.g., Ogawa, 1987; Hobbs and Ord, 1988; Karato et al. 2001; Kelemen and Hirth, 2007), transformational faulting and anticrack formation (e.g., Kirby, 1987; Green and Burnley, 1989; Burnley et al. 1991; Green and Houston, 1995; Kirby et al. 1996), and dehydration embrittlement (e.g., Griggs and Handin, 1960; Raleigh and Paterson 1965; Raleigh, 1967; Meade and Jeanloz, 1991; Nishiyama, 1992; Green and Houston, 1995; Kirby, 1995; Kirby et al. 1996; Seno and Yamanaka, 1996).

The thermal shear instability model assumes that intraslab earthquakes occur as follows. If plastic deformation progresses at a faster rate than the rate at which the generated heat dissipates, a positive feedback is produced that further promotes plastic deformation. Consequently, plastic deformation proceeds rapidly until materials in that portion of the slab start to melt, which results in sudden slips, i.e., earthquakes. The transformational faulting hypothesis assumes the following mechanism. As the slab subducts into the mantle transition zone, the phase transformation from olivine to spinel proceeds in the slab. Initially, small lens-shaped spinel crystals (spinel lenses) are formed in this phase transformation. Under the deviatoric stress field within the slab, spinel lenses grow analogously to the cracks that develop at shallow depths. These spinel lenses align along a plane that obliquely intersects with the axis of maximum compressive stress, and eventually, the crystals coalesce in that plane, which results in abrupt slips and therefore earthquakes. The dehydration embrittlement hypothesis posits that hydrous minerals that were present in the lithosphere before subduction decompose as the slab subducts and that the released $\mathrm{H}_{2} \mathrm{O}$ lowers the effective normal stress, thereby enabling brittle 
fractures that cause earthquakes. However, all three of these hypotheses are based on extrapolation from the results of laboratory experiments or theoretical calculations to simulate the great depths and scale of natural intraslab earthquakes; therefore, the exact mechanism has not yet been conclusively determined.

The present manuscript is focused on the genesis of intermediate-depth intraslab earthquakes. The transformational faulting model applies only for events that occur at the great depths of the mantle transition zone; therefore, it is not applicable to intermediate-depth events. Dehydration-related embrittlement is thought to be a promising hypothesis as a mechanism of lowering frictional strength sufficiently to generate intermediatedepth intraslab events (Nishiyama, 1992; Kirby, 1995; Seno and Yamanaka, 1996). According to this hypothesis, temperature and pressure increase within the slab with subduction, and as a result, hydrous minerals that have been fixed in the slab are decomposed. $\mathrm{H}_{2} \mathrm{O}$ is liberated by this process then lowers the effective normal stress. This effect would allow brittle faulting or dynamic slip along a fault even at depths with high lithostatic pressure. The traditional dehydration embrittlement hypothesis refers only to the embrittlement of rock that occurs during dehydration reactions. In a broader sense, however, dehydration-related embrittlement may also include the embrittlement caused by fluid released through dehydration reactions at any distance from the fault and at any time (e.g., Barcheck et al. 2012). We use the term in the latter, broader sense. The thermal shear instability model is another plausible mechanism for causing not only deep-focus earthquakes but also intermediate-depth intraslab seismicity. In some recent studies, the results of laboratory experiments and numerical simulations have supported this hypothesis (e.g., Kelemen and Hirth, 2007; Chernak and Hirth, 2011; Proctor and Hirth 2015).

In the following sections, we review recent research findings about intermediate-depth intraslab seismicity and the internal structure of subducting slabs in relation to slab metamorphism and discuss the generation mechanisms of intermediate-depth intraslab earthquakes.

\section{Review}

The double seismic zone and dehydration of metamorphosed crust and serpentinized mantle

Seismic studies of precise intermediate-depth seismicity and the detailed seismic structures of subducting slabs have provided growing evidence that supports the dehydration-related embrittlement hypothesis for earthquakes nucleation.

A non-negligible amount of $\mathrm{H}_{2} \mathrm{O}$ is contained within subducting lithosphere in the form of hydrous minerals. Hydration of oceanic lithosphere can occur in a number of tectonic settings. (1) When new lithosphere is created at a mid-ocean ridge, hydrous minerals are formed in the shallow portion of the crust by hydrothermal circulation and reactions with seawater (e.g., Dixon et al. 2002; Staudigel et al. 1995). (2) As oceanic lithosphere approaches a trench, it begins to sink and deforms under the bending force, which produces the outer rise. This bending force causes normal faulting in the trenchouter rise, and seawater enters along faults, in which hydrous minerals are then formed (Fig. 2) (e.g., Kirby, 1995; Peacock, 2001; Ranero et al. 2003; Faccenda et al. 2009; Iyer et al. 2012). (3) Seawater enters along transform faults near mid-ocean ridges because of fault movement, and hydrated minerals form along these faults as well (e.g., Bonatti and Honnorez, 1976; Gregg et al. 2007). (4) In addition, Seno and Yamanaka (1996) described a scenario whereby $\mathrm{H}_{2} \mathrm{O}$ is fixed to the oceanic plate in the form of hydrous minerals as the plate passes directly over mantle plumes or superplumes during its horizontal movement along the earth's surface. Magma of the plumes or superplumes intrudes into or accretes to the overlying oceanic lithosphere, and $\mathrm{H}_{2} \mathrm{O}$ contained in the magma is added and eventually fixed in the oceanic plate.

$\mathrm{H}_{2} \mathrm{O}$ is thus incorporated into oceanic lithosphere and fixed in the form of hydrous minerals through several different processes. It is therefore estimated that oceanic lithosphere contains a considerable amount of $\mathrm{H}_{2} \mathrm{O}$ prior to its subduction (e.g., Rüpke et al. 2004; Faccenda, 2014). When lithosphere reaches a trench, it then sinks beneath the continental plate, and its temperature and pressure rise with increasing depth. Hydrous minerals that were fixed in the oceanic lithosphere then decompose and release $\mathrm{H}_{2} \mathrm{O}$. It is proposed in the dehydrationrelated embrittlement hypothesis that this liberated $\mathrm{H}_{2} \mathrm{O}$ causes intraslab earthquakes, especially intermediatedepth events.

If hydrous minerals are present along normal faults in the trench-outer rise region prior to plate subduction, those hydrous minerals decompose and expel $\mathrm{H}_{2} \mathrm{O}$ along the faults as the plate subducts to depth. It has been proposed that intraslab earthquakes occur along these preexisting planes of weakness that originated as normal faults prior to subduction (e.g., Kirby, 1995). Jiao et al. (2000) tested this hypothesis by examining fault plane solutions of intraslab events in Tonga. The results show that for outer rise events, features of the geometry of the fault system prior to subduction persist down to c. $450 \mathrm{~km}$ depth in the subducted slab, which suggests that intraslab events down to this depth are caused by the reactivation of preexisting faults containing hydrous minerals that formed prior to subduction. Similar results were obtained for intermediate-depth intraslab events in the Middle America and Chile subduction zones (Ranero et 


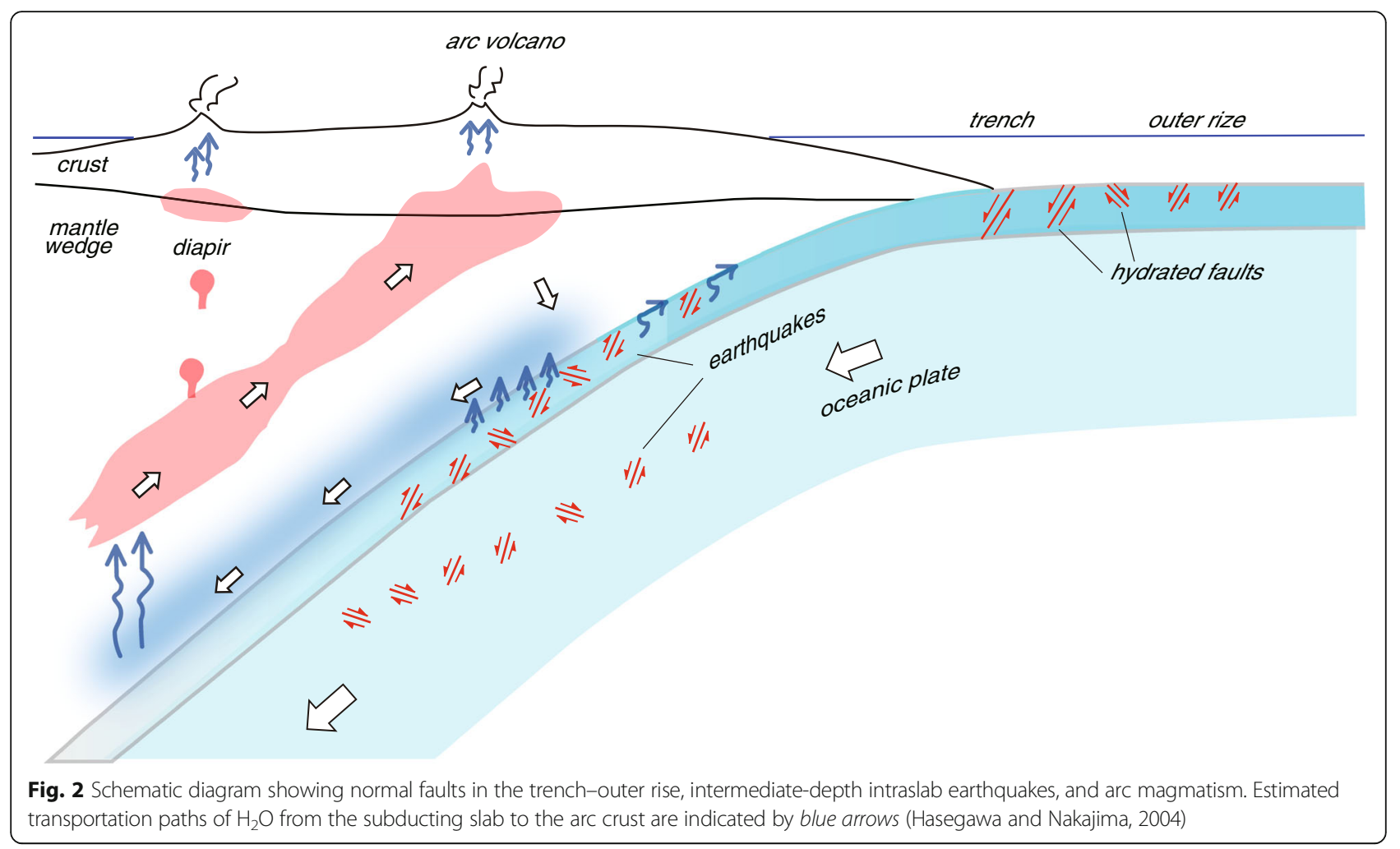

al. 2005). These observations support the dehydrationrelated embrittlement hypothesis for the genesis of intermediate-depth intraslab events, especially those that occur within the slab crust. However, subsequent studies by Warren et al. $(2007,2008)$ have shown that this issue may be more complex. By examining the fault plane orientations of intraslab events in Tonga and Middle America, they identified many subhorizontal faults, which suggest the formation of new faults. Therefore, the outer rise faults are not always reactivated. Further investigations are required to confirm the hypothesized reactivation of preexisting faults.

If intermediate-depth intraslab events are caused by dehydration-derived $\mathrm{H}_{2} \mathrm{O}$, these events would not occur everywhere throughout a slab; they would occur only in parts of the slab where hydrous minerals or $\mathrm{H}_{2} \mathrm{O}$ exist. In particular, it is hypothesized that many of these events occur at the phase boundaries (facies boundaries) of dehydration reactions across which $\mathrm{H}_{2} \mathrm{O}$ content changes. As described in detail below, recent studies have demonstrated that intermediate-depth intraslab events do in fact show such distribution. To verify whether fluidrelated embrittlement is the cause of intermediate-depth events, it is necessary to determine where hydrous minerals are present within the slab and where they decompose and expel $\mathrm{H}_{2} \mathrm{O}$. Based on experimentally and theoretically derived phase diagrams of the rocks that compose the oceanic crust and mantle (Fig. 3), Hacker et al. (2003a, b) estimated the existence range of hydrous minerals and the locations of the facies boundaries of dehydration reactions within the slabs beneath the subduction zones of Cascadia, Costa Rica and NE and SW Japan. As predicted, comparing the phase diagrams with hypocenter distributions of intermediate-depth intraslab earthquakes in these subduction zones shows that the earthquakes appear to occur only within the existence range of hydrous minerals and not outside this range. Examples from NE Japan and Costa Rica are shown in Fig. 4.

Moreover, Yamasaki and Seno (2003) found that intermediate-depth intraslab events tend to concentrate along the dehydration reaction boundaries within slabs. Based on experimentally derived phase diagrams, they estimated the locations of dehydration decomposition in metamorphosed crust and serpentinized mantle within the slabs of subduction zones beneath NE and SW Japan, Taiwan, northern Chile, Cape Mendocino, and the eastern Aleutians, and compared these estimated locations with the hypocenter distributions of intermediatedepth earthquakes. Results of this analysis for the Pacific slabs beneath NE Japan and the eastern Aleutians are shown in Fig. 5. In NE Japan, intermediate-depth earthquakes occur in a double-planed deep seismic zone 70$150 \mathrm{~km}$ in depth, with subparallel upper and lower planes 30-40 km apart from each other (Tsumura, 1973; Umino and Hasegawa, 1975: Hasegawa et al. 1978a, b). Figure $5 \mathrm{a}$ shows that the estimated locations of the 

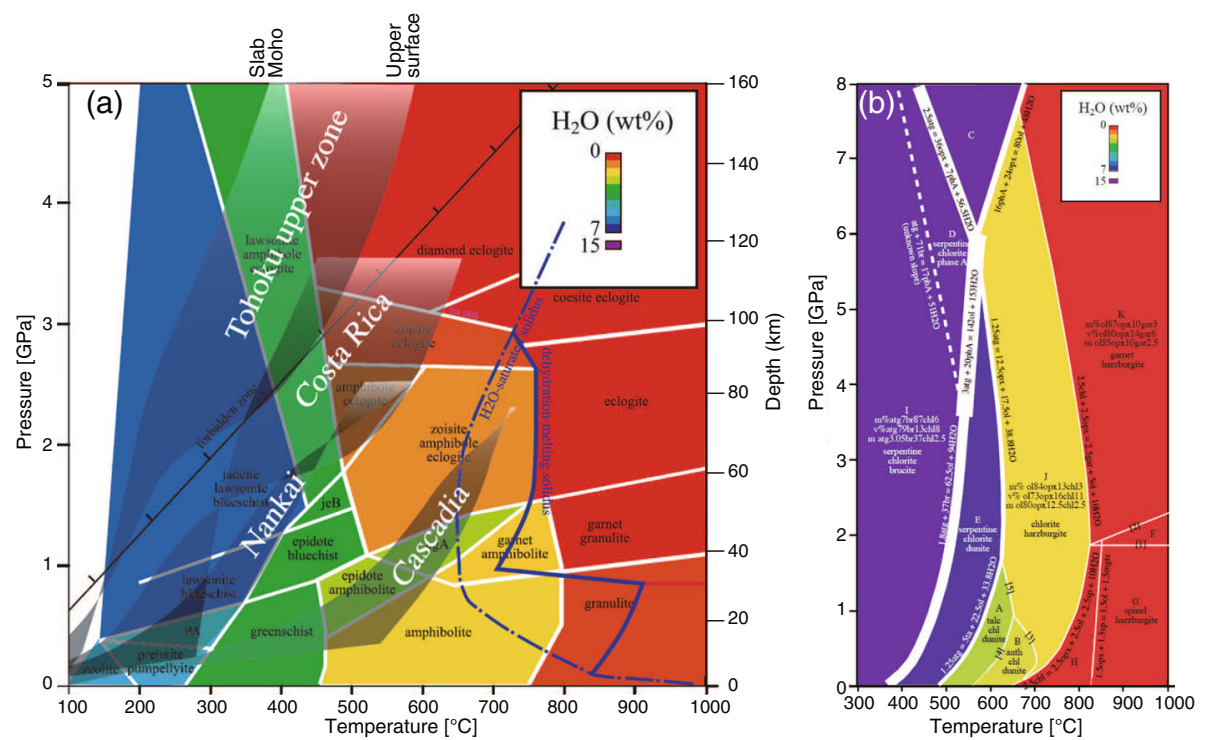

Fig. 3 Metamorphic facies and maximum $\mathrm{H}_{2} \mathrm{O}$ contents. a Mid-ocean ridge basalt (MORB) and $\mathbf{b}$ harzburgite. $\mathrm{H}_{2} \mathrm{O}$ contents in wt\% are shown by the color scale. Estimated pressure-temperature paths for the slab crust under Tohoku, Costa Rica, Nankai, and Cascadia are indicated as shaded areas in a PA, prehnite-actinolite, $e A$ epidote amphibolite, eB epidote blueschist, and jeB jadeite-epidote blueschist. (After Hacker et al. 2003b)
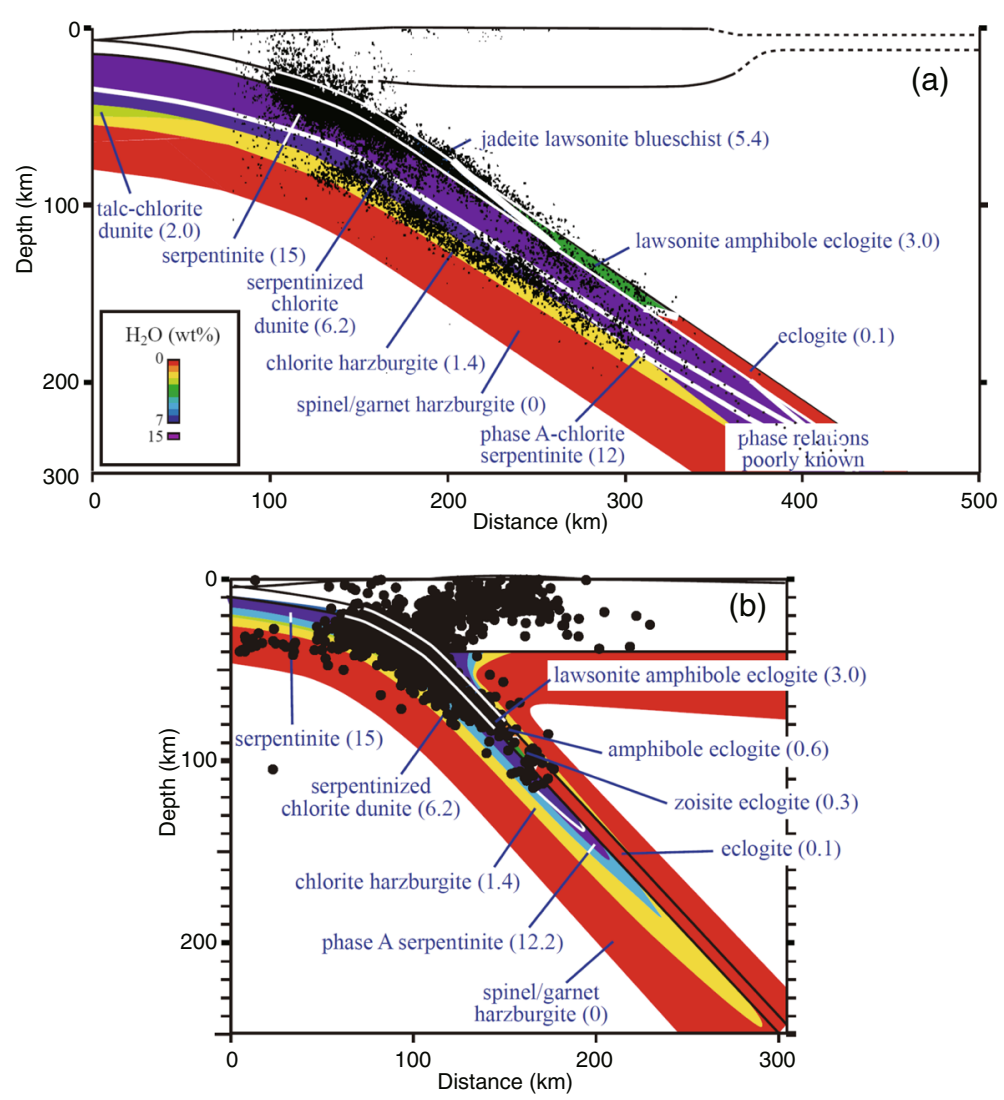

Fig. 4 Across-arc vertical cross-sections of intraslab seismicity and existence range of hydrous minerals in the slab. a Tohoku and $\mathbf{b}$ Costa Rica subduction zones. Maximum $\mathrm{H}_{2} \mathrm{O}$ contents are shown by the color scale. Dots show earthquakes. (After Hacker et al. 2003) 

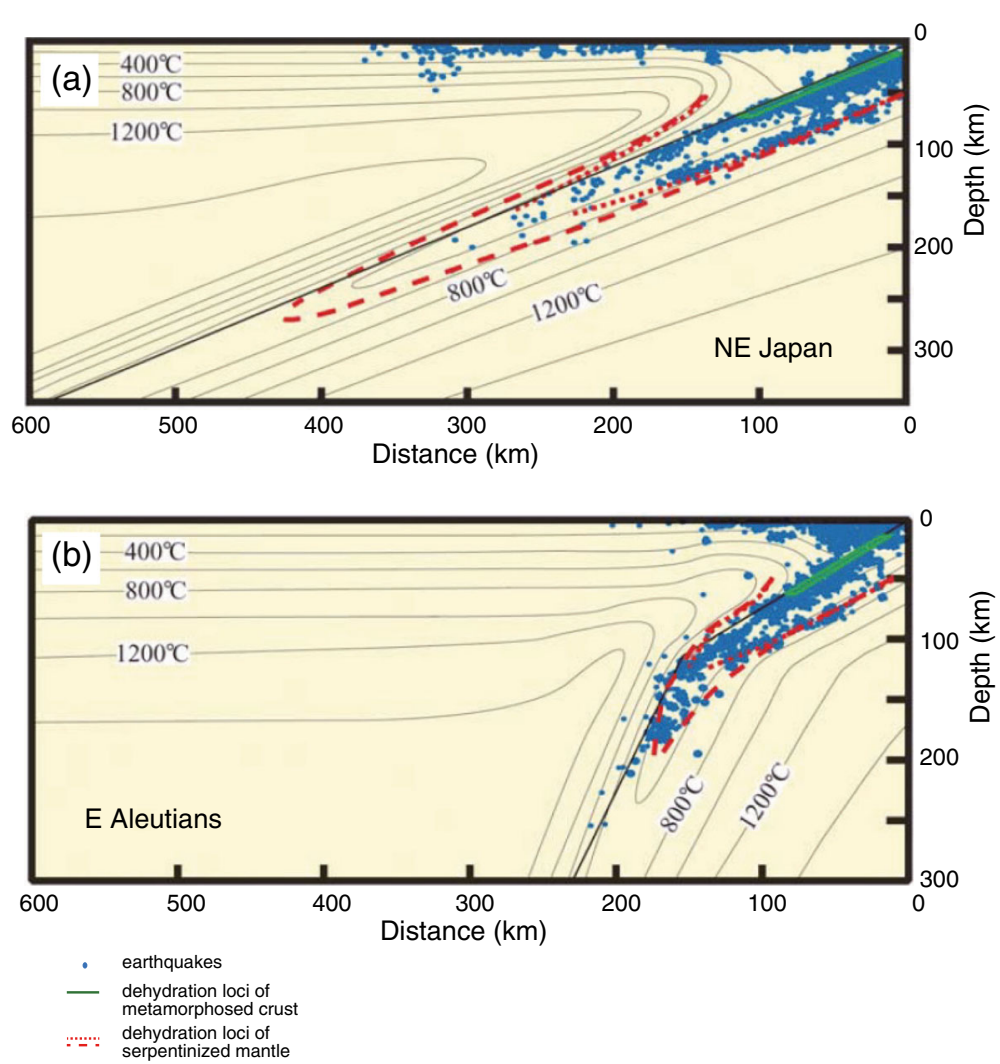

Fig. 5 Across-arc vertical cross-sections of intraslab earthquakes and dehydration loci in the slabs. a Tohoku and $\mathbf{b}$ eastern Aleutian subduction zones. Dehydration loci of metamorphosed crust and serpentinized mantle are indicated by the green and red lines, respectively. Red broken lines and red dotted lines are those based on the antigorite reaction boundaries of Ulmer and Trommsdorff (1995) and Wunder and Schreyer (1997), respectively. Blue dots are earthquakes. Thermal structure is shown as isothermal contours. (After Yamasaki and Seno, 2003)

dehydration boundary correspond approximately to the upper and lower planes of this double seismic zone. Under the eastern Aleutians, the Wadati-Benioff zone also comprises the double seismic zone, with a slightly smaller separation between the upper and lower planes than that of the NE Japan slab. Figure $5 b$ again shows that the estimated dehydration reaction boundaries roughly correspond to the upper and lower seismic planes. Similar results were also obtained for the remaining four subduction zones included in the study. This correspondence further explains why the lowerplane events of the double seismic zone are generated in the middle of the lithospheric mantle, as previously reported by Peacock (2001).

Since the discovery of an unambiguous double seismic zone in Tohoku (Hasegawa et al. 1978a, b), numerous subduction zones across the world have been similarly investigated, and double seismic zones have been detected with certainty in several subduction zones (e.g., Frohlich, 2006), such as in slabs subducted below Hokkaido (Suzuki et al. 1983), Kuril-Kamchatka (Kao and Chen, 1994), Alaska (Abers, 1992, 1996), Cascadia (Cassidy and Waldhauser, 2003), Mendocino (Smith et al. 1993), northern Chile (Comte and Suarez, 1994; Comte et al. 1999), New Zealand (Reyners et al. 1997), Tonga (Kawakatsu, 1985, 1986), and northern Taiwan (Kao and Rau, 1999). However, double seismic zones are not apparent in all subduction zones worldwide. Furthermore, even when a double subduction zone is present, its depth may range from c. 40 to $180 \mathrm{~km}$, and the separation distance between the upper and lower planes may range between c. 10 and $40 \mathrm{~km}$.

Hypocenters of earthquakes must be accurately determined, especially their focal depths, to evaluate whether a double seismic zone is present in a given subduction zone. Dense seismic observation network data are required for accurate determination of earthquake hypocenters, but few subduction zones are installed with such dense networks. Without relying on data from such local seismic networks, Brudzinski et al. (2007) investigated a number of subduction zones worldwide to evaluate whether double seismic zones were present. They used global seismic network data and selected events with well-constrained focal depths, such as those determined based on depth phases. Using hypocenter data from the EHB catalog (Engdahl et al. 1998; Engdahl and 
Villaseñor, 2002), they verified the presence of the double seismic zone by investigating whether two peaks appear in the frequency distribution of intermediatedepth intraslab earthquakes with respect to the distance from the slab upper surface. The two peaks in the frequency distribution are interpreted to correspond to the upper and lower planes of the double seismic zone. It thus became clear that (1) the two peaks were apparent for all 30 of the investigated subduction zones, and (2) the distance between the two peaks, i.e., the separation distance between the upper and lower planes, varies by subduction zone, and is proportional to the age of the subducting plate (Fig. 6). These findings are consistent with the predictions of the dehydration-related embrittlement hypothesis. In fact, the lowerplane events correspond to the expected positions of dehydration decomposition in the serpentinized mantle in the slab, as shown in Fig. 6.

Detailed analyses of intermediate-depth intraslab earthquakes in NE Japan have further revealed a characteristic structure of the Wadati-Benioff zone. Igarashi et al. (2001) reported that normal fault type events also occur at the top of the upper plane of the double seismic zone in the depth range of c. $70-100 \mathrm{~km}$. In terms of focal mechanisms, the Wadati-Benioff zone beneath NE Japan is triple-planed; from top to bottom, these three planes are characterized by normal fault, down-dip compressional and down-dip extensional events. Wang
(2002) argued that plate unbending combined with dehydration-related embrittlement may account for the morphology and stresses of this triple-planed seismic zone. Metamorphic reactions densify materials and therefore induce tensile stress in the uppermost transformed crust. This tensile stress, as well as high pore fluid pressure, in the uppermost slab crust thus generates the normal fault type seismicity that occurs there. A recent study by Nakajima et al. (2013) revealed that even in a small seismic cluster, normal fault type events occur just $1 \mathrm{~km}$ above the down-dip compressional events in the lower crust of the subducting Pacific Plate beneath Niigata, NE Japan. These observations provide evidence for the role of densification-related stresses caused by metamorphic reactions and fluid-related embrittlement in earthquake nucleation within the slab crust.

\section{Seismic wave velocity structure and upper-plane seismicity in the slab crust \\ $A$ belt of intraslab seismicity and phase transition in the slab crust beneath eastern Japan}

As described in the previous section, the locations of upper-plane events in the Pacific slab crust beneath NE Japan roughly correspond to the dehydration reaction boundaries of the metamorphosed crust (Fig. 5a). Recent studies have revealed a more detailed spatial distribution of this upper-plane seismicity, as well as a clear relationship between that distribution and the seismic wave

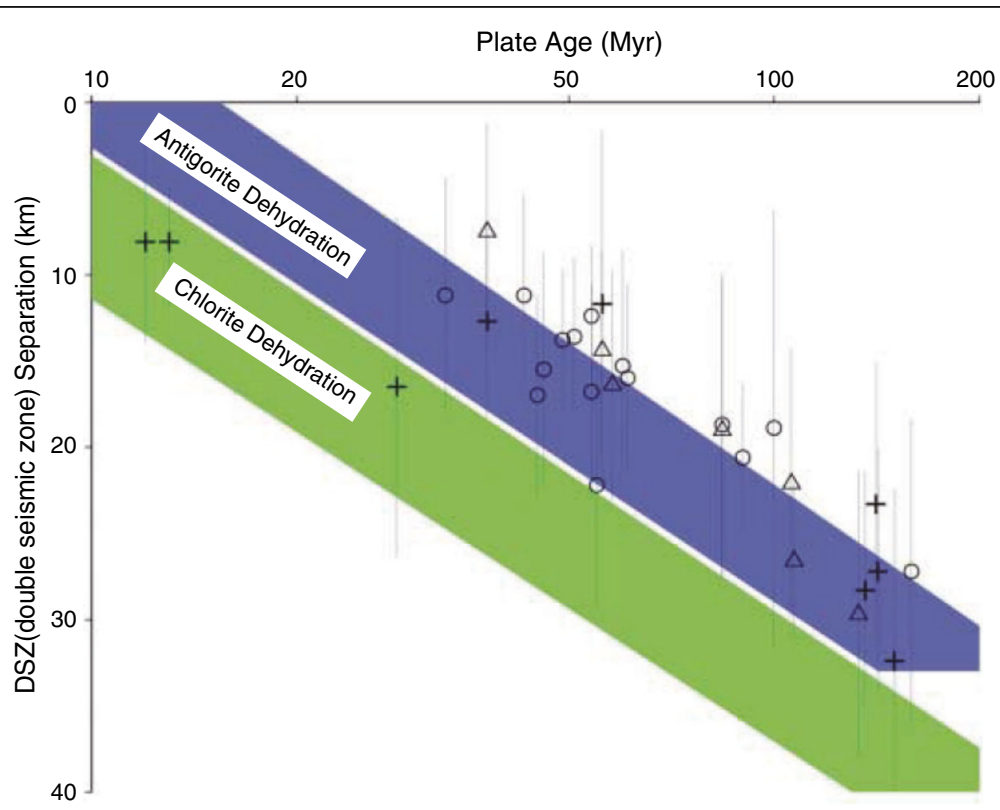

Fig. 6 Separation of the double seismic zone plotted against the age of the subducting slab. Distances between the upper and lower seismic planes are shown by three different symbols: triangles show typical down-dip compression overlying down-dip extension, circles indicate a different pattern, and crosses denote unknown. Vertical lines attached to the symbols are one-standard deviation uncertainties from Gaussian fits. Predicted separations of the double seismic zones based on the lower seismic planes resulting from the dehydration of antigorite and chlorite based on Hacker et al. (2003) are shown as blue and green shaded areas, respectively. (After Brudzinski et al. 2007) 
velocity structure of the slab crust, which is likely associated with dehydration reactions. This relationship may be well explained if dehydration-related embrittlement is the cause of intermediate-depth intraslab events.

The hypocenter distribution of events that occurred in the crust of the Pacific slab under eastern Japan is shown in Fig. 7a (Kita et al. 2010). As shown with arrows in this figure, events in the slab crust in Tohoku and eastern Hokkaido form a significant belt-like seismic zone nearly parallel to the 70-90 km depth contours of the upper surface of the slab. The frequency distributions of events in the slab crust as a function of depth along lines (b) through (l) in Fig. 7a are shown in Fig. 7b-l, respectively. The distribution for each of these lines shows a clear peak between the depths of 70 and $90 \mathrm{~km}$, as indicated in the figure by arrows. Figure 8a shows an across-arc vertical cross-section of intraslab seismicity under central Tohoku. The belt-like concentrated earthquake activity shown in the plan view of Fig. 7a is visible at c. $70-90 \mathrm{~km}$ in depth in the vertical cross-sectional view in Fig. 8a. Kita et al. (2006) named this seismically active band-shaped region of the slab crust the "upper-plane seismic belt." If intermediate-depth intraslab events are caused by dehydration-related embrittlement, this upper-plane seismic belt should be located in the existence range of hydrous minerals in the slab crust, particularly around the facies boundaries of the dehydration reaction.

Beneath Kanto, the upper-plane seismic belt is not parallel to the $70-90-\mathrm{km}$ depth contours of the upper surface of the slab; it becomes deeper locally and is oblique to the $70-90-\mathrm{km}$ depth contours, as shown in Fig. 7a. This difference is caused by the shielding effect of the Philippine Sea slab that directly overlies the Pacific slab (Hasegawa et al. 2007, 2009, 2016). Highquality data obtained in Japan with a nationwide seismic

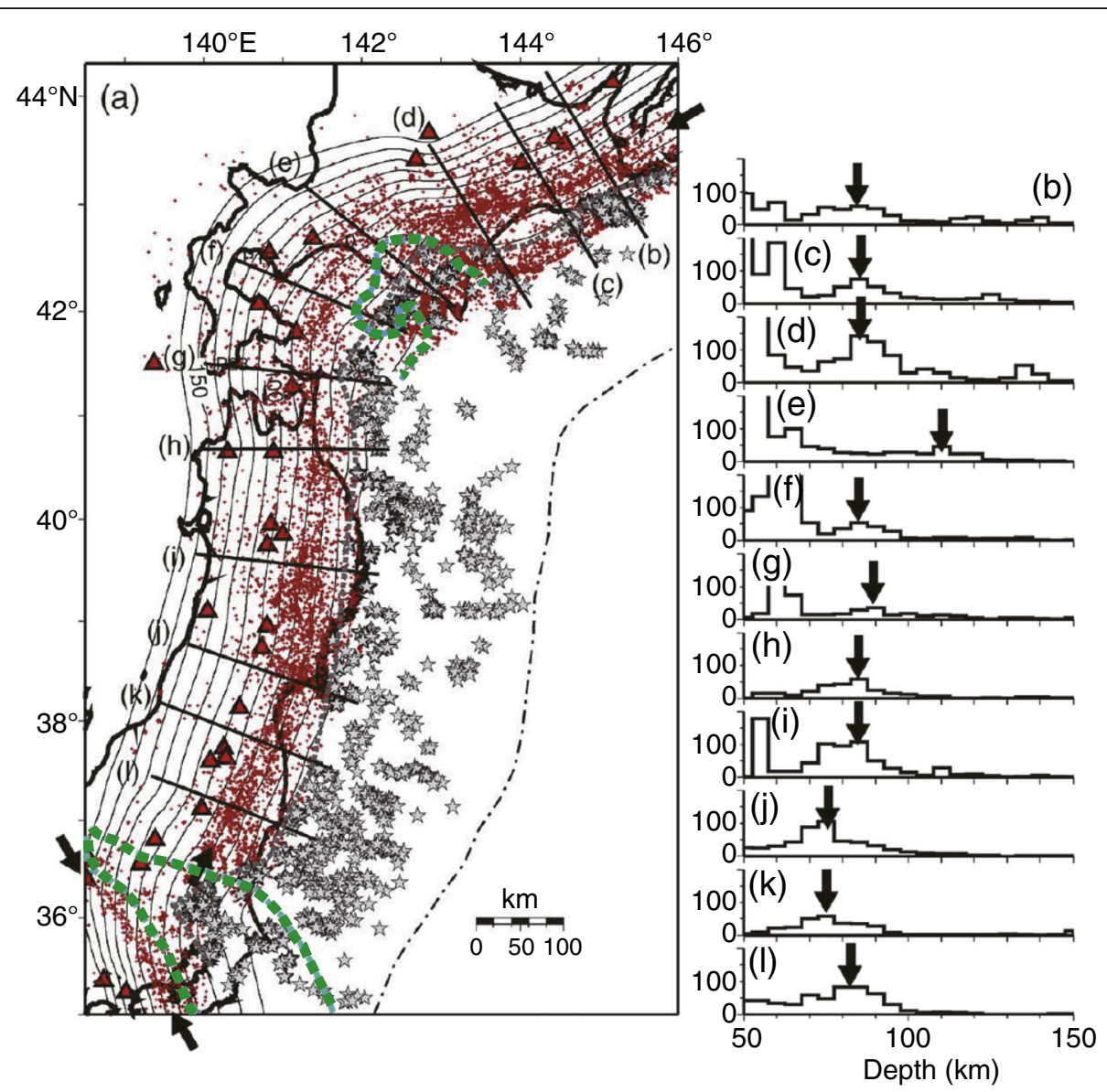

Fig. 7 A belt of upper-plane seismicity in the slab crust. a Hypocenter distribution of earthquakes in the crust of the Pacific Plate subducting under eastern Japan. Events 0-10 km below the upper plate surface are shown by red dots. Bold arrows denote estimated locations of the upper-plane seismic belt. The contact zone between the Philippine Sea and Pacific Plate beneath Kanto and that between the subducted crust and the Pacific Plate beneath western Hokkaido are indicated by blue thick broken curves. Solid curves, red triangles, and gray stars denote iso-depth contours of the upper plate surface, active volcanoes, and small repeating earthquakes, respectively. b-I Frequency distributions of upper-plane events along the lines $b$ through / in Fig. 7a plotted against depth. Frequency is plotted for intervals of $10 \mathrm{~km}$. The black arrows show the peak that corresponds to the upper-plane seismic belt. (After Kita et al. 2010) 

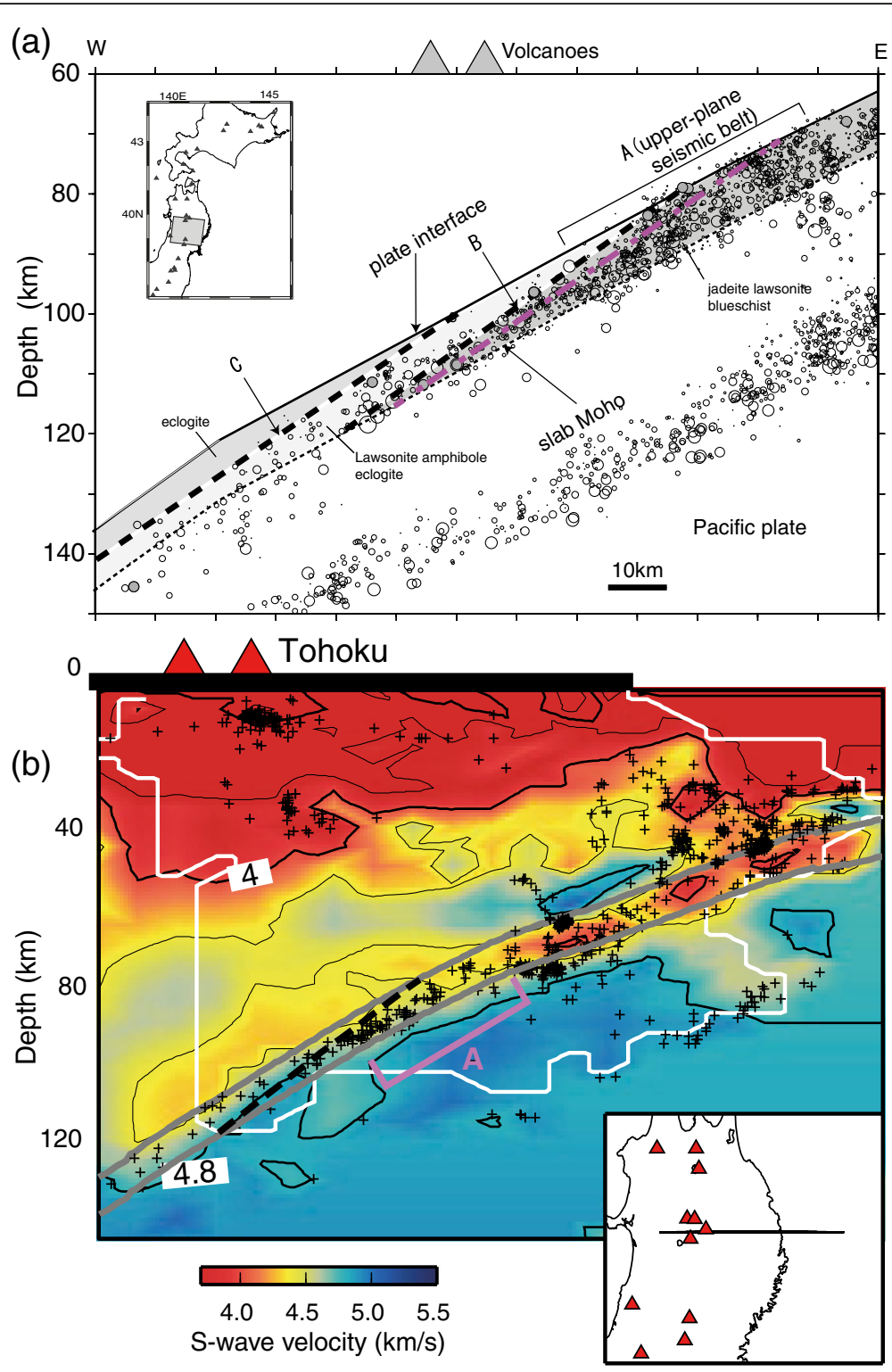

Fig. 8 Seismicity and facies boundaries in the slab crust and low S-wave velocity layer. a Across-arc vertical cross-section of intraslab earthquakes and facies boundaries in the crust of the Pacific slab under central Tohoku (modified from Kita et al.(2006)). Facies boundaries are indicated by broken black lines and a long and short dashed red line. Open circles are earthquakes. Solid and thin dashed lines are the upper plate interface and the Moho within the slab, respectively. b Across-arc vertical cross-section of S-wave velocity in central Tohoku (Tsuji et al. 2008). S-wave velocity is indicated by the color scale at the bottom. Solid line is the upper plate interface, and A denotes the upper-plane seismic belt

network have enabled precise estimation of the positions and shapes of both the Pacific and the Philippine Sea Plates subducting under the Japanese archipelago, as well as the contact of the two plates over a wide area under Kanto (Nakajima and Hasegawa, 2007, 2010; Nakajima et al. 2009b; Hirose et al. 2008; Kita et al. 2010a; Uchida et al. 2009, 2010). As shown in Fig. 9a, b, the Pacific slab under Kanto is directly overlain by, and in contact with, the Philippine Sea slab. The extent of the slab-slab contact area, which is enclosed by two thick, broken green lines in Fig. 7a, corresponds approximately to the extent of the Kanto Plain. Figure 7a shows that the down-dip end of the contact area is parallel to the upper-plane seismic belt, adjacent to its shallow side, and oblique to the $70-90-\mathrm{km}$ depth contours of the upper surface of the slab. This clear spatial correspondence can be understood if we consider the following scenario. (1) The Pacific slab subducting under Kanto is capped by the overlying Philippine Sea slab. (2) This cap prevents temperature rise in the Pacific slab due to heating from the hot mantle wedge above. (3) Therefore, the phase transition associated with the 

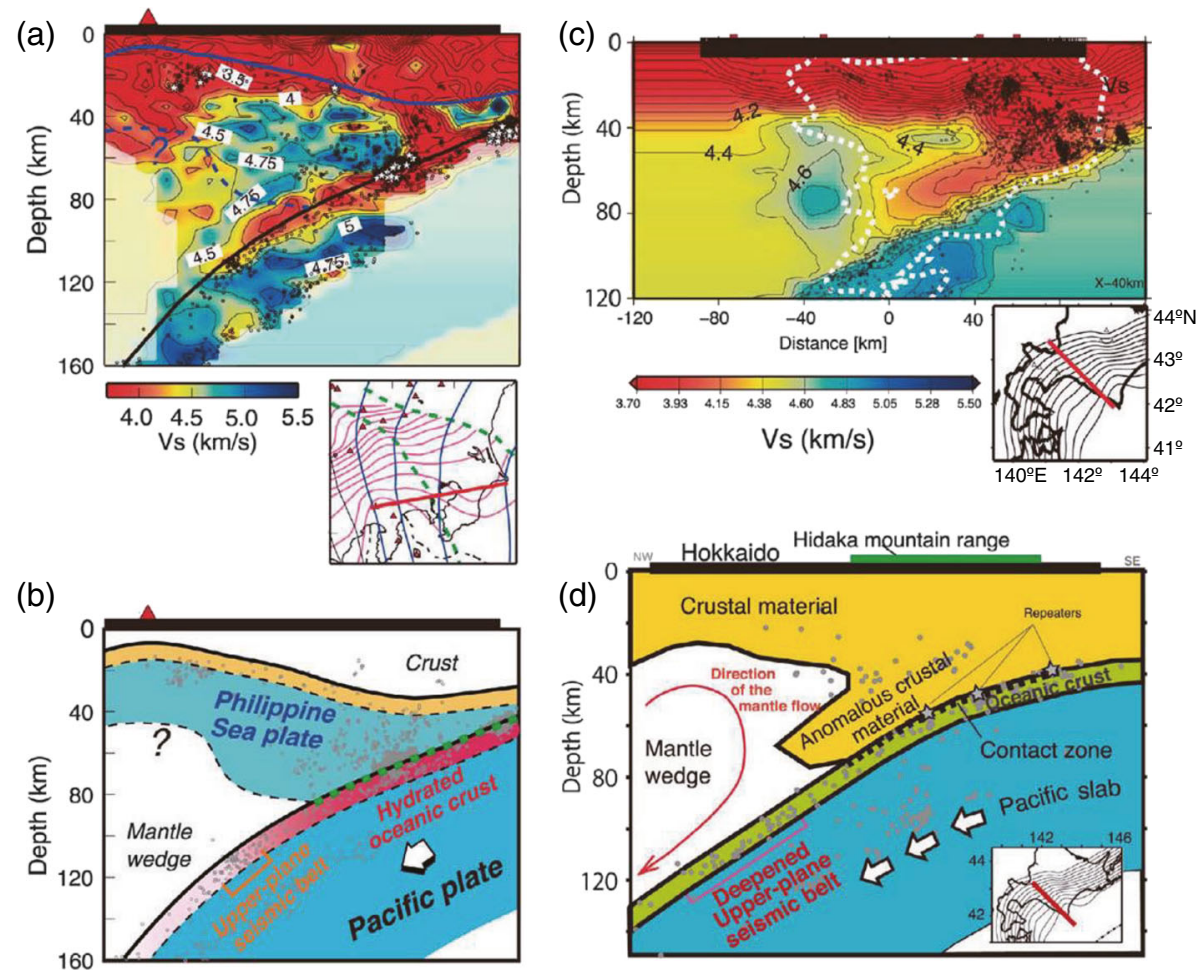

Fig. 9 The contact of the Pacific slab with the overlying Philippine Sea slab or forearc crust. a Vertical cross-section of S-wave velocity along a line under Kanto in the inset map and $\mathbf{b}$ schematic figure showing the contact between the Philippine Sea and Pacific slabs (Nakajima et al. 2009b). c Across-arc vertical cross-section of S-wave velocity under western Hokkaido along a line in the inset map and $\mathbf{d}$ schematic figure showing the contact between the subducted forearc crust and the Pacific slab (Kita et al. 2010a). S-wave velocity is indicated by the color scale at the bottom

dehydration reaction is significantly delayed in the $\mathrm{Pa}$ cific slab crust. (4) Consequently, the upper-plane seismic belt in the Pacific slab deepens locally and is oblique to the 70-90 km depth contours of the upper surface of the slab, as shown in Fig. 7a.

A similar local deepening of the upper-plane seismic belt was detected below SW Hokkaido, associated with the junction of the NE Japan and Kuril arcs (Kita et al. 2010). As indicated by the arrows in Fig. 7a, e, the upper-plane seismic belt becomes deeper locally in the area beneath this arc-arc junction and reaches the vicinity of the $110-\mathrm{km}$ depth contour of the slab's upper surface. Beneath Hokkaido, on the southwestern edge of the Kuril arc, the Pacific Plate is subducting obliquely to the trench axis. This oblique subduction causes the forearc sliver of the Kuril arc to collide with the forearc of the NE Japan arc (e.g., Kimura, 1986). A seismic tomography study by Kita et al. (2010) clearly imaged the crust portion of the colliding forearc, which has subducted into the mantle wedge and reached the upper surface of the Pacific slab immediately below (Fig. 9c, d). The estimated contact area between the subducted crust thus imaged, and the Pacific slab is enclosed by a thick, broken green line in Fig. 7a. This figure shows that the contact area corresponds closely with the local deepening of the upper-plane seismic belt. Therefore, similarly to the case in Kanto, the local deepening of the upper-plane seismic belt in SW Hokkaido can be understood if we consider the following. (1) The Pacific slab under SW Hokkaido is capped by subducted crust that directly overlies it (2) his capping prevents the Pacific slab from being heated by the mantle wedge immediately above it (3) herefore, the phase transition and dehydration is delayed in the slab crust (4) his delay causes local deepening of the upper-plane seismic belt in this region, as well (Kita et al. 2010).

If the phase transition of the dehydration reaction occurs in the slab crust, seismic wave velocity is expected to become faster across the phase boundary. Therefore, it can be verified based on the distribution of seismic wave velocities obtained through seismic tomography whether the phase transition of the dehydration reaction causes the formation of the upper-plane seismic belt. Figure 8b shows an across-arc vertical cross-section of S-wave velocity in central Tohoku obtained by Tsuji et al. (2008) using the double-difference (DD) tomography method of Zhang and Thurber (2003). A low-velocity layer that corresponds to the slab crust extends down to the depth of the upper-plane seismic belt ( $\mathrm{A}$ in the figure), and no further. Figure 10a shows the distribution of S-wave velocity 


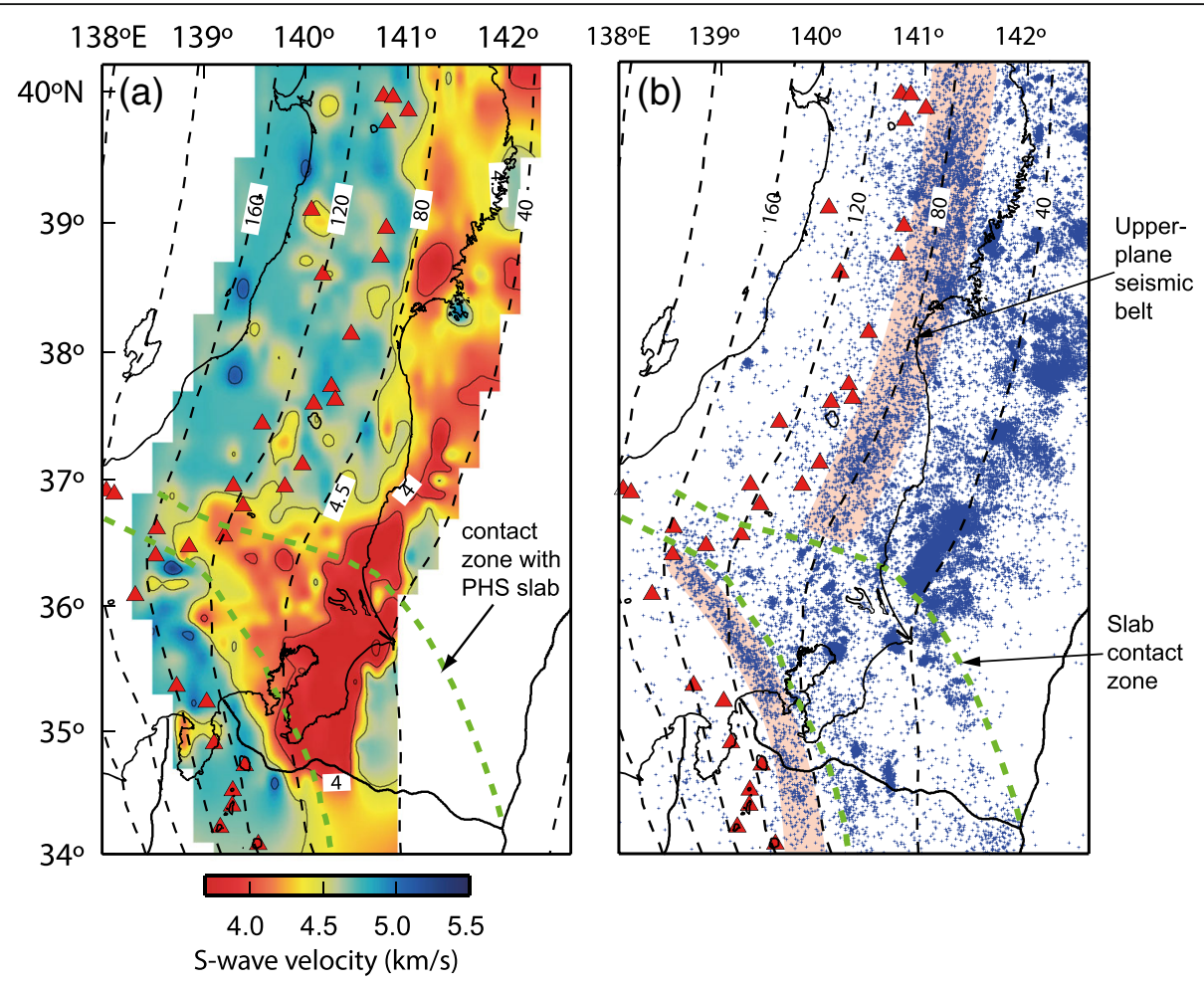

Fig. 10 Seismicity and S-wave velocity in the crust of the Pacific slab. a S-wave velocity distribution in the crust of the Pacific slab under NE Japan on a curved plane $5 \mathrm{~km}$ below the upper plate surface. $\mathbf{b}$ Hypocenters of earthquakes within the crust of the Pacific slab. Events 0-10 km below the upper plate surface are shown as blue dots, and the upper-plane seismic belt is shown in pink. Broken black curves denote iso-depth contours of the upper plate surface. The slab-slab contact zone is enclosed by two green broken curves. Red triangles are active volcanoes. (After Nakajima et al. 2009b)

in the Pacific slab crust estimated through DD tomography (Nakajima et al. 2009). As also shown in Fig. 8b, the low-velocity layer under Tohoku extends to a depth of approximately $80 \mathrm{~km}$, the depth of the upper-plane seismic belt, and no further. In contrast, the low-velocity layer under Kanto becomes locally deeper in the area that corresponds to contact with the overlying Philippine Sea slab; this area is enclosed by two thick, broken green lines in Fig. 10a. Figure 10a shows that the areal extent of the lowvelocity layer is reasonably consistent with the slab-slab contact area. Comparison of Fig. 10a with the hypocenter distribution in the slab crust (Fig. 10b) shows that the location of the locally deepened upper-plane seismic belt is in excellent agreement with the down-dip end of the lowvelocity layer in the slab crust. Consequently, the obtained distribution of S-wave velocity in the slab crust further supports the prediction that the phase transition is locally delayed in this region.

Mode-converted seismic waves at the upper plate interface from intermediate-depth intraslab events also provide evidence that the seismic low-velocity layer corresponds to the subducting slab crust (e.g., Matsuzawa et al. 1986, 1990; Zhao et al. 1997; Abers, 2005). P-to-S mode-converted waves at the upper surface of the plate propagate through the slab crust for longer distances than do direct P- and S-waves; therefore, their arrivaltime data are convenient for estimating the seismic velocity structure within the slab crust. A recent analysis of P-to-S converted waves under central Tohoku by Shiina et al. (2013) reported that the seismic low-velocity layer persists down to the depth of the upper-plane seismic belt in the subducted oceanic crust. Estimated P-wave velocity at the depth of the upper-plane seismic belt in the low-velocity crust is c. $10 \%$ lower than theoretically predicted values for metamorphosed mid-ocean ridge basalt (MORB). Shiina et al. (2013) proposed the coexistence of fluids and hydrous minerals to explain this substantial decrease in P-wave velocity, which provides additional seismic evidence that earthquakes in the slab crust are facilitated by fluid-related embrittlement.

Thus far, we have discussed the phase transition based on the seismic observations that the belt-like concentration of seismic activity is detectable in the slab crust and that the seismic wave low-velocity layer extends down to the depth of this upper-plane seismic belt. Here, we also compare the locations of the upper-plane seismic belt and the down-dip end of the seismic low-velocity layer with thermal-petrological estimates of the positions of the dehydration reaction boundaries in the slab crust, although there is high uncertainty in their positions 
because of error in the estimation of temperature distribution in the subducting slab. The phase boundaries of jadeite lawsonite blueschist (hereafter JLB) $\rightarrow$ lawsonite amphibole eclogite (hereafter LAE) and of LAE $\rightarrow$ eclogite in the slab crust beneath central Tohoku are indicated by the broken black lines $\mathrm{B}$ and $\mathrm{C}$, respectively, in Fig. 8a. These boundaries are estimated based on the MORB phase diagram of Hacker et al. (2003b) (Fig. 3a) and the temperature distribution of the slab by Peacock and Wang (1999) (the P-T trajectory of the oceanic crust of Tohoku shown in Fig. 3a). The upper-plane seismic belt indicated as $\mathrm{A}$ in the figure is located near or on the shallower side of the phase boundary of JLB with a $\mathrm{H}_{2} \mathrm{O}$ content of $5.4 \% \rightarrow \mathrm{LAE}$ with a $\mathrm{H}_{2} \mathrm{O}$ content of $3.0 \%$, as indicated by $\mathrm{B}$ in the figure. These findings are roughly consistent with the predictions based on the dehydration-related embrittlement hypothesis. Furthermore, earthquakes occur only in the lower crust on the deeper side of the phase boundary of JLB $\rightarrow$ LAE, and no longer occur after exceeding the phase boundary of $\mathrm{LAE} \rightarrow$ eclogite, as indicated by $\mathrm{C}$ in the figure. This observation is also consistent with the predictions drawn from the dehydration-related embrittlement hypothesis. For another example, the estimated dehydration reaction boundary based on the MORB phase diagram by Omori et al. (2009) and the temperature distribution of the slab given by van Keken et al. (2002) is indicated by a thick, one-dot-chain red line in Fig. 8a. In this case, the phase boundary also roughly coincides with the position of the upper-plane seismic belt as predicted based on the dehydration-related embrittlement hypothesis.

The production rate of dehydration-derived $\mathrm{H}_{2} \mathrm{O}$ appears to clearly explain the formation of the belt-like concentration of upper-plane seismicity at depths of $\mathrm{c}$. $80-120 \mathrm{~km}$ in the oceanic crust of the Pacific slab subducting under eastern Japan. Abers et al. (2013) calculated the accumulated amount of dehydration-derived $\mathrm{H}_{2} \mathrm{O}$, the $\mathrm{H}_{2} \mathrm{O}$ production rate, and the overall system volume change from the dehydration reaction, as a function of depth for two representative slabs: the Pacific slab beneath eastern Hokkaido as a cold slab and the Philippine Sea slab beneath Kii as a warm slab (Fig. 11b-d). Their calculations were based on estimated $\mathrm{P}-\mathrm{T}$ (pressure-temperature) trajectories for the subducting slab crust on the $\mathrm{P}-\mathrm{T}$ diagram of maximum $\mathrm{H}_{2} \mathrm{O}$ contents for a hydrated MORB metabasalt, as shown in Fig. 11a. The frequency of earthquakes within the slab crust as a function of depth beneath eastern Hokkaido (Kita et al. 2010) is shown in Fig. 11e for comparison. These figures show that the $\mathrm{H}_{2} \mathrm{O}$ production rate, the overall volume change from dehydration, and the frequency of earthquakes in the slab crust below eastern Hokkaido (blue lines in Fig. 11c-e) all have peaks at a depth of c. $80-90 \mathrm{~km}$. Although Fig. 11c, d is based on calculations for the top of the slab, the strong correlations of both the $\mathrm{H}_{2} \mathrm{O}$ production rate and the total volume change with seismicity in the slab crust strongly support the interpretation that embrittlement caused by increased pore pressure from dehydrationderived $\mathrm{H}_{2} \mathrm{O}$ is the reason for the upper-plane seismic belt.

At present, however, there are large uncertainties in estimating the temperature distribution within subducting slab crust; therefore, further verification of the thermal-petrological estimates of the position of the dehydration reaction boundary is necessary. Nevertheless, the following seismic observations strongly support the dehydration-related embrittlement hypothesis: (1) that there is a belt of upper-plane seismicity nearly parallel to the $80-90 \mathrm{~km}$ depth contours of the upper slab surface, (2) that the seismic low-velocity layer corresponding to the slab crust persists down to the upperplane seismic belt and, no further, (3) that both the upper-plane seismic belt and the down-dip end of the seismic low-velocity layer deepen locally under Kanto and SW Hokkaido, with these local deepenings coinciding spatially with the areas of contact with the Philippine Sea slab and the overlying subducted forearc crust, and (4) that both the $\mathrm{H}_{2} \mathrm{O}$ production rate and the net volume change caused by dehydration in the slab crust have peak depths at c. $80-90 \mathrm{~km}$, which is approximately consistent with the location of the upper-plane seismic belt.

\section{The upper-plane seismic belt and seismic low-velocity layer in slab crust in other subduction zones}

Does a similar upper-plane seismic belt form in the slab crust in other subduction zones? The formation of upper-plane seismic belts should be common to all subduction zones if they are caused by fluids expelled by the dehydration of slab crust materials.

Abers et al. (2013) systematically investigated the relationship between trends in earthquake locations and thermal-petrological conditions within the crust of subducting slabs by comparing several well-characterized subduction zones from different parts of the world. They found that in young (and therefore warm) subduction zones, earthquakes preferentially lie within the slab mantle or very close to the slab Moho. In contrast, in old (and therefore cold) subduction zones, earthquakes occur throughout the oceanic slab crust as well as the slab mantle. They proposed that separation into these two classes is caused by differences in the $\mathrm{P}-\mathrm{T}$ paths that the slab crust follows as it descends into the mantle. The subducting slab $\mathrm{P}-\mathrm{T}$ trajectories of young and warm subduction zones and those of old and cold subduction zones encounter different facies boundaries, which produce differences in the way that $\mathrm{H}_{2} \mathrm{O}$ is released via dehydration. Estimated temperatures along 


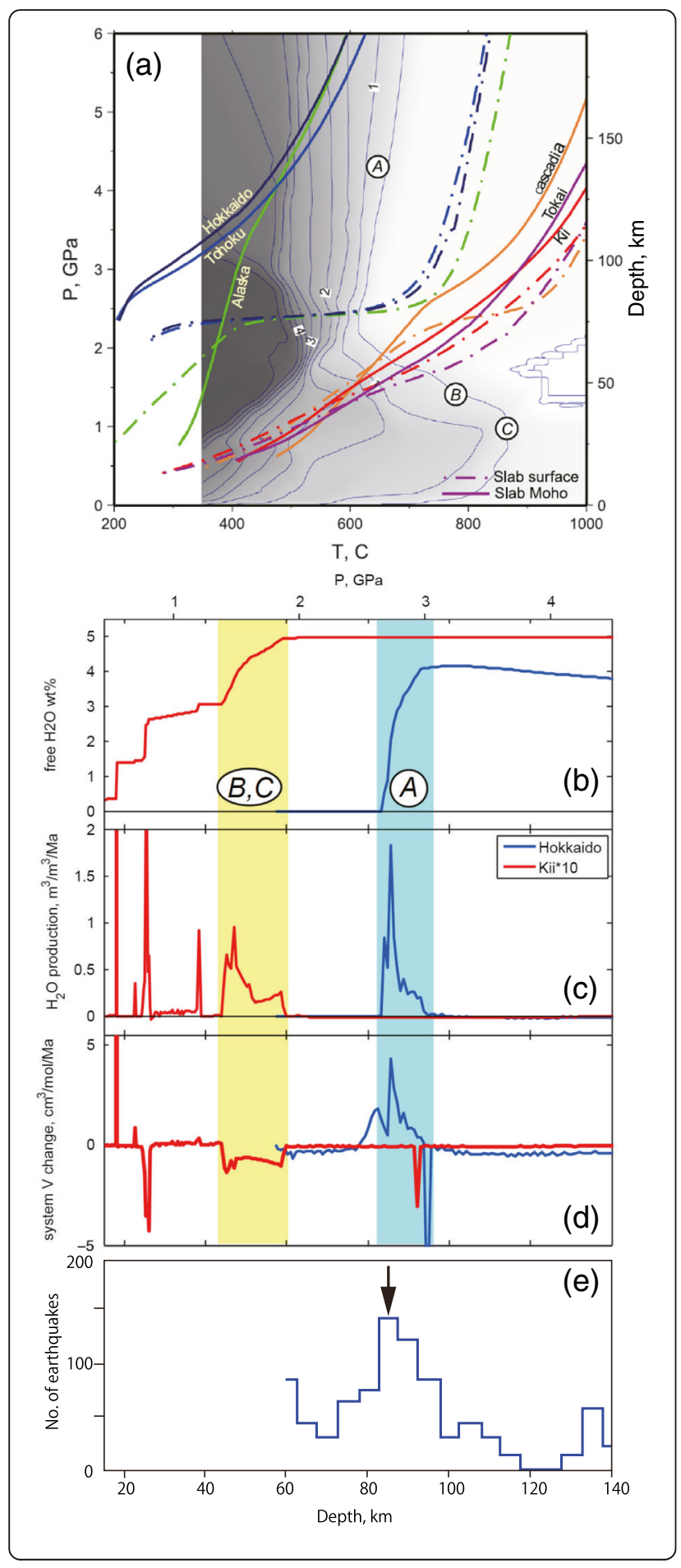

Fig. $11 \mathrm{P}-\mathrm{T}$ path, $\mathrm{H}_{2} \mathrm{O}$ production, system volume change, and frequency of earthquakes in the crust. a Pressure-temperature $(P-T)$ paths of the subducting oceanic crust for six subduction zone segments plotted on a diagram of maximum $\mathrm{H}_{2} \mathrm{O}$ contents (Abers et al. 2013). P-T paths for the upper slab surface and slab Moho are shown as colored solid and dot dashed lines, respectively. Shading shows maximum $\mathrm{H}_{2} \mathrm{O}$ contents in wt $\%$ for a hydrated metabasalt of MORB bulk composition (Hacker, 2008). Major dehydration reactions are indicated by $A$ (lawsonite breakdown), B (zoisite breakdown), and $C$ (amphibole breakdown). $\mathbf{b}-\mathbf{d}$ Evolution of pore fluid pressure and $\mathrm{H}_{2} \mathrm{O}$ content for cold and warm slabs (Abers et al. 2013). Hokkaido is indicated by blue lines as a representative cold slab and Kii by red lines as a representative warm slab. $\mathbf{b}$ Accumulated dehydration-derived $\mathrm{H}_{2} \mathrm{O}$ content in wt\% as dehydration reactions progress. c Rate of $\mathrm{H}_{2} \mathrm{O}$ production, with Kii scaled by a factor of 10 relative to Hokkaido. $\mathbf{d}$ Total system (solid $+\mathrm{H}_{2} \mathrm{O}$ ) volume. Shaded in light blue and yellow denote depth intervals of major dehydration for Hokkaido and Kii, respectively. $A$, $B$, and $C$ denote specific reactions shown in Fig. 11a. e Frequency of upper-plane earthquakes beneath central Hokkaido (Fig. 7d) as a function of depth (Kita et al. 2010)

the upper surface of the slab and the slab Moho for each of the six subduction zone segments are plotted on a pressure-temperature diagram of $\mathrm{H}_{2} \mathrm{O}$ content for hydrated MORB in Fig. 11a. The figure shows that the P$\mathrm{T}$ paths for the cold and warm slabs are characterized by considerably different conditions. At high pressures, the main dehydration reaction is the breakdown of lawsonite (A in Fig. 11a), and the crusts of cold slabs, such as those beneath Hokkaido, Tohoku, and central Alaska, experience this dehydration reaction to eclogite. At lower pressures, the breakdown of zoisite and amphibole (B and $\mathrm{C}$ in Fig. 11a) takes place and the crusts of warm slabs, such as those beneath Cascadia, Tokai, and Kii, undergo this dehydration reaction.

The above two dehydration reaction boundaries produce different $\mathrm{H}_{2} \mathrm{O}$ production rates, as shown in Fig. 11b, c. These figures show a gradual release of $\mathrm{H}_{2} \mathrm{O}$ in the depth range of c. 20-60 km for the warm slab beneath Kii, but a considerably abrupt release in the depth range of c. $80-95 \mathrm{~km}$ for the cold slab beneath Hokkaido. The production rate of $\mathrm{H}_{2} \mathrm{O}$ in cold slabs is an order of magnitude higher than that for warm slabs (Fig. 11c). Moreover, because of the positive Clapeyron slope, the overall volume change from the dehydration reaction is positive for the cold slab (Fig. 11d), which causes effective increase in pore fluid pressure and thus favors overpressuring. The large $\mathrm{H}_{2} \mathrm{O}$ production rate and the increase in total volume through the breakdown of blueschist are likely to promote earthquake occurrence in cold slabs. In contrast, the slow $\mathrm{H}_{2} \mathrm{O}$ production rate and decrease in total volume through the breakdown of zoisite and amphibole probably inhibit, or at least do not promote, earthquake occurrence in the crusts of warm slabs. Abers et al. (2013) showed that the boundary between these two cases can be expressed by 
the thermal parameter (Kirby, 1995; (plate age) $\times($ vertical descent rate of plate)) of c. 500-1000 km.

The results given by Abers et al. (2013) predict that the formation of the upper-plane seismic belt in the slab crust does not occur only in the subducting Pacific slab beneath eastern Japan but occurs also commonly in cold subduction zones with thermal parameters larger than c. $500-1000 \mathrm{~km}$. In contrast, in the crust of warm slabs with thermal parameters less than c. 500-1000 km, earthquakes occur preferentially within the slab mantle, and therefore, the upper-plane seismic belt does not form. Dense local seismic network data and intense seismic activity in the slab crust are required to ascertain the presence of an upper-plane seismic belt. Few such subduction zones exist, and consequently, clear evidence of the presence of upper-plane seismic belts in other subduction zones has not yet been reported.
The nationwide dense seismic network of Japan also covers the SW Japan subduction zone where the Philippine Sea slab is subducting beneath it. The age of the subducting Philippine Sea Plate at the trench axis varies in the along-arc direction. It is as young as $15-25 \mathrm{Ma}$ between western Shikoku and Tokai, whereas it is older in Kanto (>40 Ma) and Kyushu (>50 Ma) (Seno and Maruyama, 1984). Therefore, it may be possible to ascertain the presence or absence of the upper-plane seismic belt. Figure 12 shows the hypocenter distribution of events in the crust of the Philippine Sea slab. This figure shows that events in the slab crust under the region from western Shikoku to Tokai are distributed to a maximum depth of c. 40, except for some outliers. In contrast, the down-dip end of the seismicity in the slab crust is deeper under regions where older lithosphere of the Philippine Sea Plate is subducting; it is as deep as $80-90 \mathrm{~km}$ in Kanto and is c. $100 \mathrm{~km}$ deep

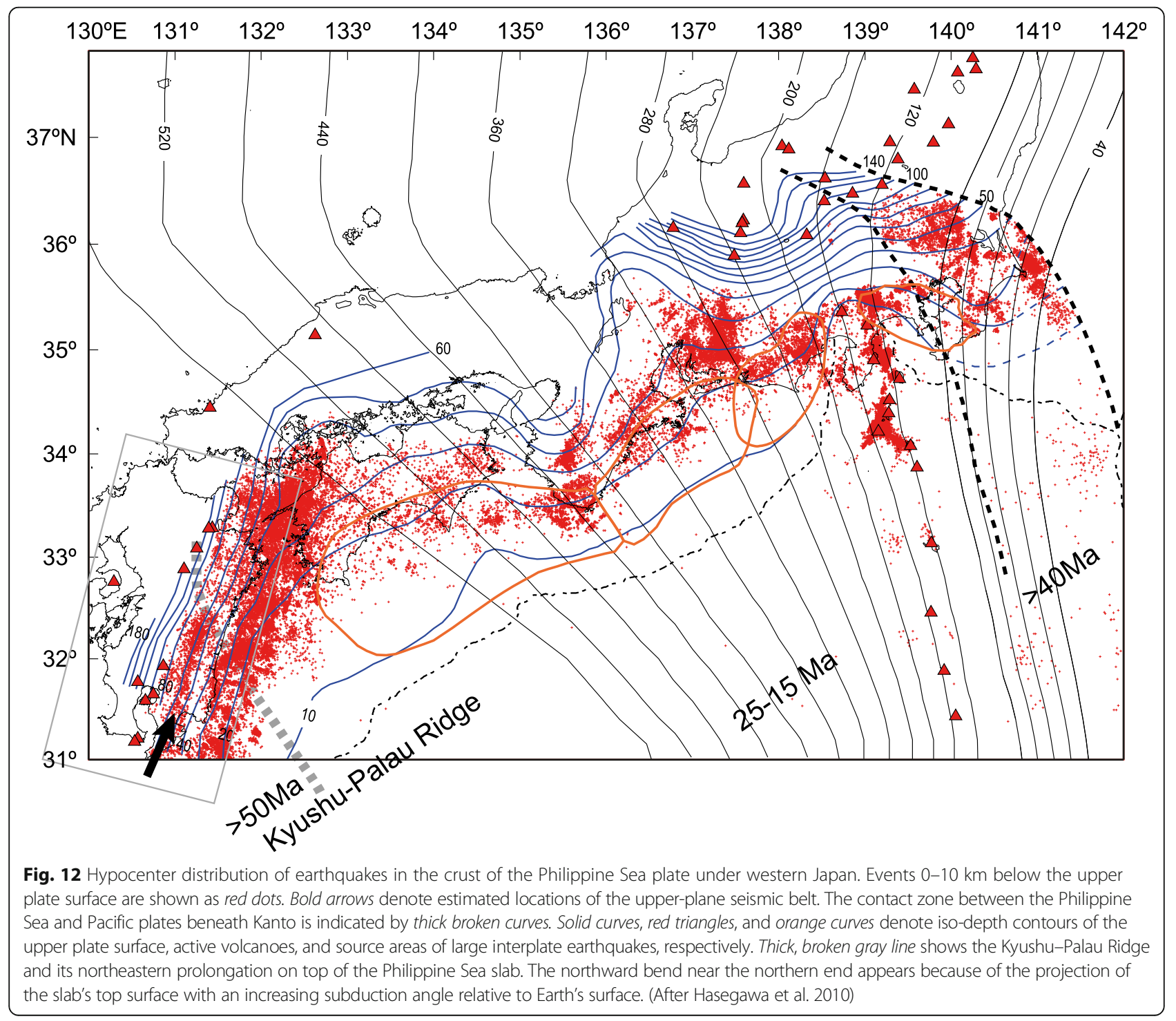


in Kyushu. These findings are consistent with the expectation that the colder Philippine Sea slab under Kanto and Kyushu is able to generate earthquakes at greater depths.

Another prominent feature of Fig. 12 is a belt-like concentration of seismicity, as indicated by the arrow, that is nearly parallel to the c. $60 \mathrm{~km}$ depth contour of the upper surface of the slab under southern Kyushu (strictly speaking, under the region to the south of the NW extension of the Kyushu-Palau ridge (thick broken line)). This feature is similar to the upper-plane seismic belt detected in the crust of the Pacific slab under eastern Japan. Although a similar belt-like concentration of seismic activity seems to be detectable in the depth range of 40-50 km beneath Kanto and may reflect the same activity, it is not discussed further here because it is unclear. In contrast, such a significant belt-like concentrated earthquake zone is not apparent in the much larger area from western Shikoku to Tokai. This alongarc variation in crustal seismicity is also inferred to be the result of the difference in age (or temperature) of the Philippine Sea slab (Hasegawa et al. 2009). The thermal parameters calculated by Syracuse et al. (2010) indicate that the slab beneath southern Kyushu at $31.22^{\circ} \mathrm{N}$, $130.57^{\circ} \mathrm{E}$ has a value of $1560 \mathrm{~km}$, which means that it belongs to the cold slab group. In contrast, the slab beneath Nankai at $35.3^{\circ} \mathrm{N}, 137.3^{\circ} \mathrm{E}$ has a value of $450 \mathrm{~km}$, which means it belongs to the warm slab group. Consequently, the belt-like concentrated seismicity in the crust of the older Philippine Sea slab beneath southern Kyushu, which occurs at depths approximately $20 \mathrm{~km}$ shallower than the belt of the Pacific slab beneath Hokkaido and Tohoku, is probably caused by the same dehydration reactions of slab crust materials. The absence of such a clear belt-like concentrated seismicity in the crust of the younger portion of the Philippine Sea slab beneath the area from Tokai to western Shikoku (or northern Kyushu) is attributed to the warmer conditions there.

As shown in Fig. 12, the estimated upper-plane seismic belt in southern Kyushu abruptly disappears north of the NW prolongation of the Kyushu-Palau ridge (thick, broken gray line in Fig. 12). Figure 13 illustrates an alongarc vertical cross-section of earthquakes that occurred within the rectangle shown in Fig. 12. This figure also shows that the upper-plane seismic belt, which is visible at depths of c. $50-70 \mathrm{~km}$, and abruptly disappears to the north of the NW prolongation of the Kyushu-Palau ridge, as shown by the thick, broken red line. The sudden disappearance of the upper-plane seismic belt strongly suggests that the formation of the belt is controlled by slab age or temperature, as shown in Fig. 11, because the slab age abruptly changes between the north and south of the Kyushu-Palau ridge.

Studies of several subduction zones have revealed the presence of seismic low-velocity zones that correspond to the subducting crust, although the upper-plane seismic belt has not yet been detected at other sites (e.g., Fukao et al. 1983; Hori et al. 1985; Hori, 1990; Helffrich, 1996; Reyners et al. 1999; Abers, 2000, 2005; Bostok et al. 2002; Kodaira et al. 2000, 2004; Eberhart-Phillips et al. 2005; Hirose et al. 2008a, b; Syracuse et al. 2008; Rondenay et al. 2008, 2010; Abers et al. 2009, 2013; Eberhart-Phillips and Bannister, 2015). These seismic low-velocity layers in subducting crust have been interpreted as evidence for the presence of hydrated rocks or fluids liberated by dehydration reactions. Typical examples of these layers are shown in Figs. 14, 15, and 16.

Figure 14 shows across-arc vertical cross-sections of the P-wave velocity in the slab below Nicaragua and Costa Rica estimated based on inversions of P- and Swave arrival times of local earthquakes (Syracuse et al. 2008). Nicaragua and Costa Rica lie on the Caribbean Plate, under which the young Cocos Plate is subducting northeastward at a rate of c. $88 \mathrm{~mm} /$ year. Inversion results show the presence of P-wave low-velocity zones in this area that probably correspond to the crust of the subducted Cocos Plate. This observation is particularly clear in Fig. 14c, which shows a P-wave low-velocity zone that extends as far as $70 \mathrm{~km}$ in depth. The down-dip end may be produced by the phase transformation of materials that compose the slab crust. Moreover, P-wave low-velocity zones were also imaged at the locations of the slab mantle c. $20-30 \mathrm{~km}$ below Wadati-Benioff zone seismicity, depths of c. $140 \mathrm{~km}$ beneath Nicaragua, and c. $60 \mathrm{~km}$ beneath Costa Rica. Syracuse et al. (2008) interpreted these low-velocity zones beneath Nicaragua as $10-20 \%$ serpentinized mantle of the subducted Cocos Plate, which may introduce relatively high amounts of $\mathrm{H}_{2} \mathrm{O}$ into the mantle wedge beneath Nicaragua.

Figure 15 shows across-arc vertical cross-sections of $\mathrm{P}$ wave velocity and $\mathrm{Vp} / \mathrm{Vs}$ (the ratio of P-wave velocity to $\mathrm{S}$ wave velocity) along the northern Hikurangi subduction zone of New Zealand. These data were obtained by inverting arrival-time data of local earthquakes (Eberhart-Phillips and Bannister, 2015). Onshore-offshore marine-seismic data were also incorporated in these inversions, which improved constraints on the shallow portion of the target area. In this area, the Pacific Plate is subducting obliquely under the Australian Plate, on which the North Island of New Zealand lies, at a rate of $42-47 \mathrm{~mm} /$ year. The obtained seismic velocity images shown in Fig. 15 clearly indicate the presence of a P-wave low-velocity zone and a high $\mathrm{Vp} / \mathrm{Vs}$ zone to depths of $80-100 \mathrm{~km}$ associated with the oceanic crust of the subducted Pacific slab. This zone of low Vp and high $\mathrm{Vp} / \mathrm{Vs}$ is probably caused by hydrated rocks or fluids liberated by dehydration reactions.

Figure 16a shows an across-arc seismic section beneath central Alaska obtained through seismic receiverfunction analyses (Rondenay et al. 2008, 2010). In this 


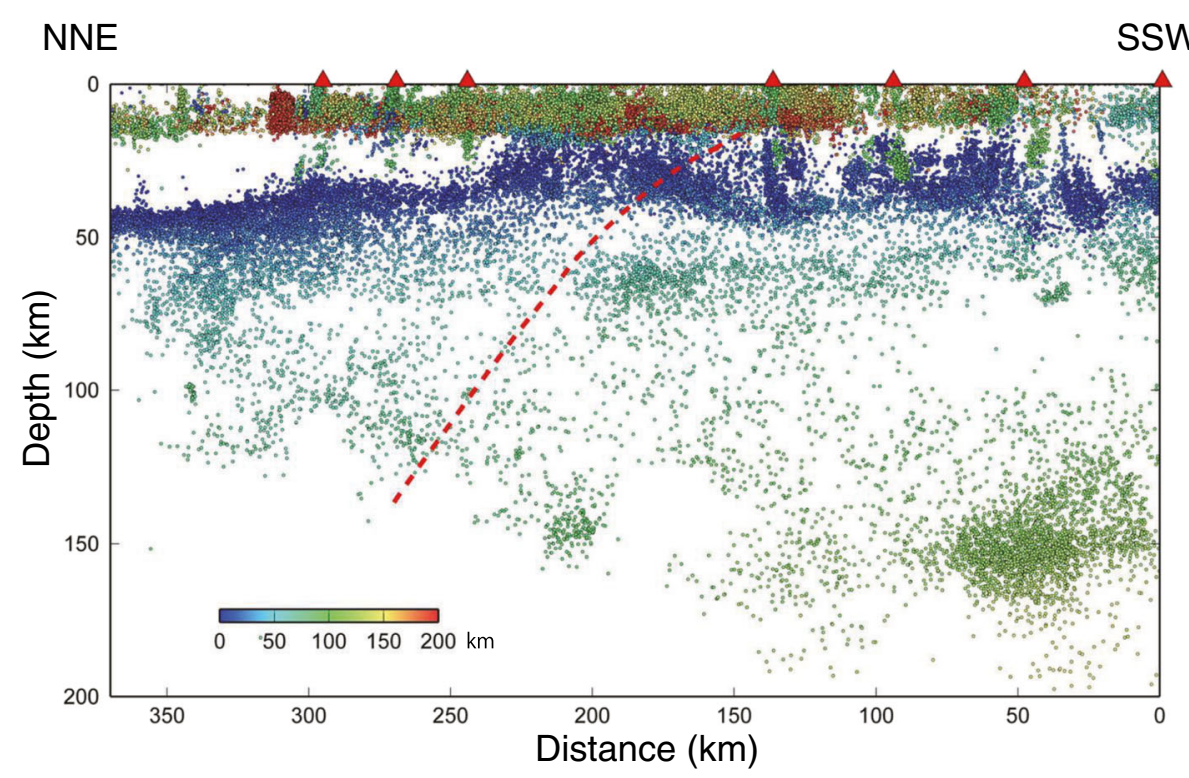

Fig. 13 Along-arc vertical cross-section of earthquakes beneath Kyushu. Earthquakes that occurred in the rectangular region shown in Fig. 12 are shown as circles. The distance of each event from the east-southeastern edge of the rectangular region is shown as the color scale. The estimated northeastern prolongation of the Kyushu-Palau ridge from the top of the slab is shown as the thick, broken red line. Red triangles at the top denote volcanoes

region, the Pacific Plate has an age of 35-45 Ma at the trench axis and converges with the North American Plate at a rate of c. $55 \mathrm{~mm}$ /year, which produces a thermal structure of the slab that falls in the middle of the range globally (Kirby et al. 1996; Rondenay et al. 2008). Along the profile shown in Fig. 16a, the Yakutat terrane, which has a thickness from 15 to $30 \mathrm{~km}$ and can be described as an oceanic plateau, is subducting. This subduction was clearly imaged as a dipping low-velocity layer to a depth of c. $130 \mathrm{~km}$. Intraslab earthquakes occur near the top of the subducting slab crust at depths shallower than c. $80 \mathrm{~km}$ and then gradually deepen toward the oceanic Moho with increasing depth. Both the intraslab seismicity and the low-velocity slab crust terminate at c. $120-130 \mathrm{~km}$ in depth, which suggests that the eclogite-forming phase transition operates in this depth range (Abers et al. 2013).

Figure 16b shows an across-arc seismic migration image below central Cascadia obtained via seismic receiver-function analyses (Abers et al. 2009). In this region, the Juan de Fuca Plate, with an age of 6-9 Ma at the trench axis, is subducting obliquely at a rate of 35$45 \mathrm{~mm} /$ year. This slow subduction rate in the vertical direction and the young age of the plate make it one of the hottest slabs in the world (Wada and Wang, 2009; Syracuse et al. 2010). The subducting slab crust was clearly imaged as a dipping low-velocity layer with a thickness of 7-9 km to a depth of c. $40 \mathrm{~km}$. Almost all intraslab earthquakes in this region are located at or just below the slab Moho, and very little seismicity is produced within the subducting crust. The shallow termination depths of the low-velocity slab crust and the very low level of seismicity in the slab crust are consistent with the high-temperature conditions of this slab (Abers et al. 2013). Based on estimations of the thermal structure of the slab and on the phase diagram of crust materials, Rondenay et al. (2008) compared two subduction zones, central Alaska and central Cascadia, and claimed that the termination depths of the low-velocity subducting crust correspond to eclogitization of the metamorphosed crust through dehydration of hydrous minerals, which depends largely on the thermal structure of the subducting slab crust. Overall, seismicity in the slab crust appears to be closely related to the dehydration reactions, although the upper-plane seismic belt is not apparent even in the case of the cold slab described here, which can most likely be attributed to the very small number of earthquake data.

All of these observations seem to support the dehydration-related embrittlement hypothesis as the mechanism behind the genesis of intermediate-depth events within the slab crust.

\section{Seismic wave velocity structure and lower-plane seismicity in the slab mantle: seismic low-velocity zones and serpentinized slab mantle}

Until recently, seismic imaging of the subducting slab was performed not to image detailed, inhomogeneous structures inside the slab, but to determine the shape of the subducting slab as a seismic high-velocity zone separate from the surrounding mantle with normal seismic wave velocity. Very high spatial resolution is required to 


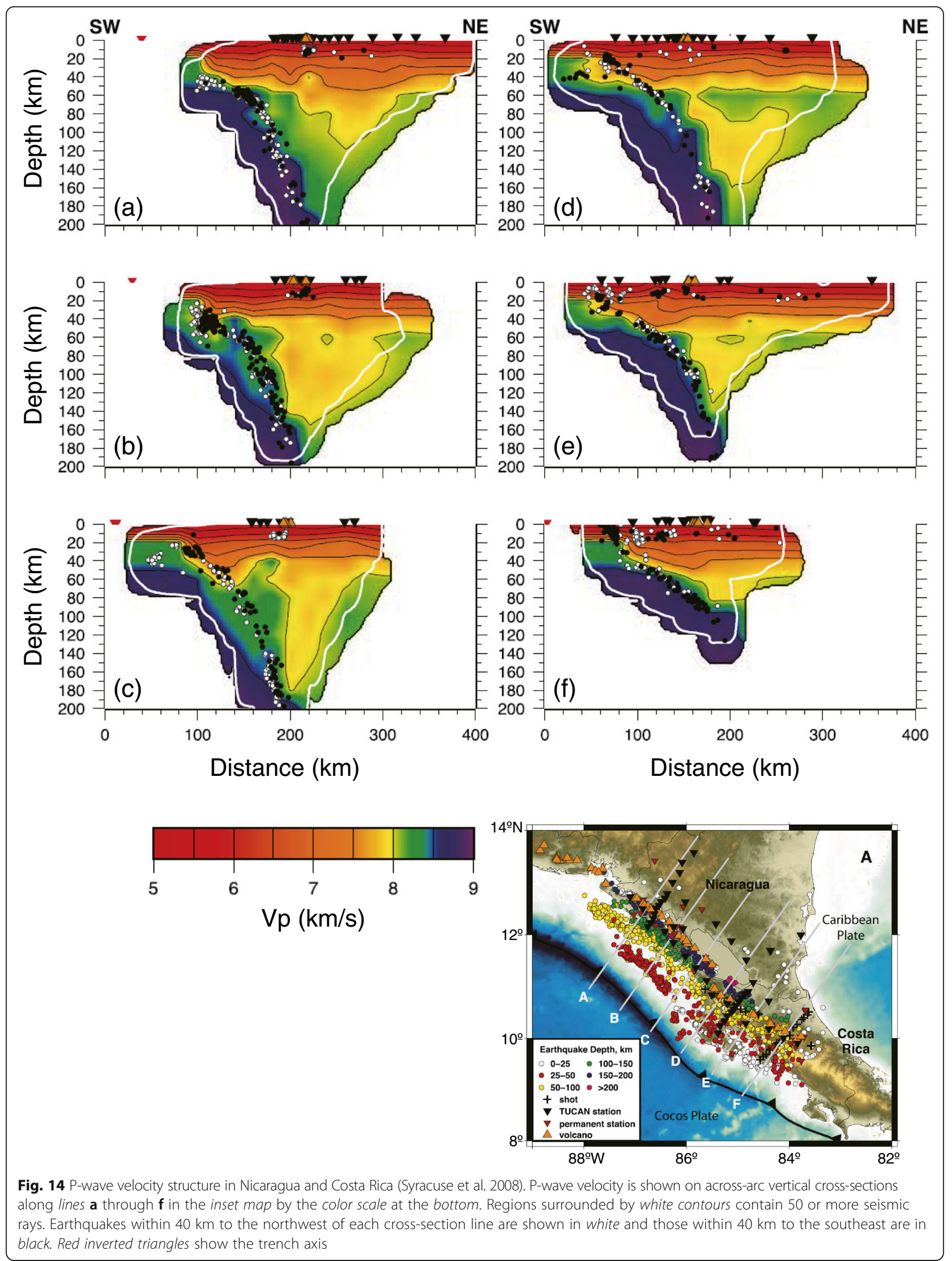




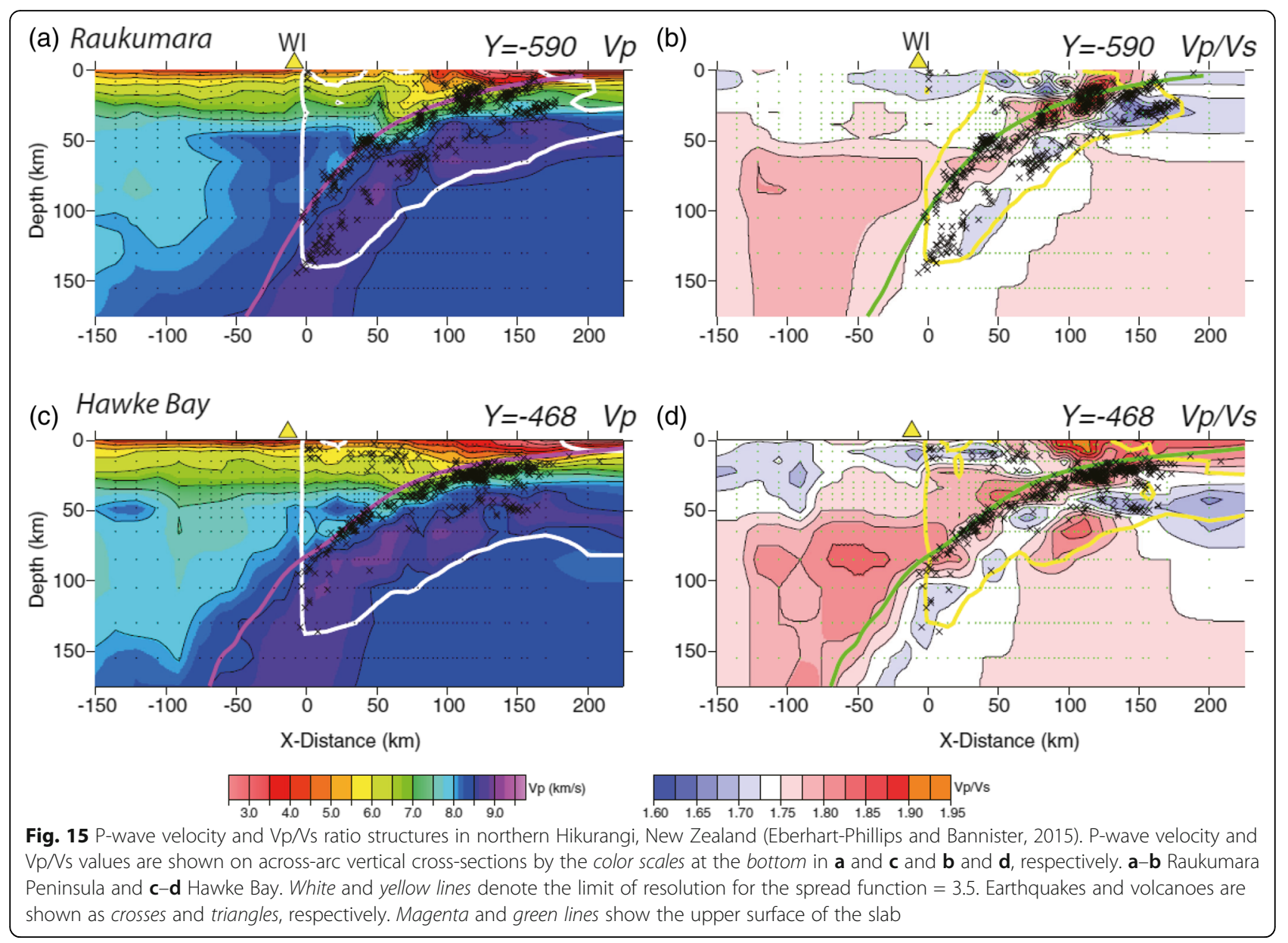

detect the inhomogeneous structure inside the slab, and in the past, this resolution could not be achieved. A high-density seismic network is required for such highresolution seismic imaging, and recently, this resolution has become possible through dense observation network data. The nationwide dense seismic network has been deployed in Japan, a typical subduction zone with a very high seismic activity, and this development has enabled us to image even the internal structure of the subducted slab below Japan. The seismic low-velocity layer that persists to the depth of the upper-plane seismic belt in the slab crust, as described in the "The double seismic zone and dehydration of metamorphosed crust and 149 serpentinized mantle" section, is one example of such internal structure. Recent seismic tomography studies based on nationwide dense network data have also revealed the detailed structure of seismic velocity inside even the slab mantle.

If hydrous minerals or the $\mathrm{H}_{2} \mathrm{O}$ released through dehydration reactions are present in some regions of the slab mantle, those regions are expected to have low seismic wave velocities. Precisely, imaging of heterogeneous structures inside the slab mantle with seismic tomography can be challenging, however. The slab mantle exists at greater depths than the slab crust, and consequently, seismic rays arriving at seismic stations above earthquake hypocenters do not sufficiently crisscross the slab mantle, which results in poor resolution in seismic velocity imaging. Therefore, research into the heterogeneous seismic velocity structure of the slab mantle remains very limited.

If many densely distributed events occur in a particular area, that area can be imaged very precisely via seismic tomography because a large number of ray paths will crisscross the area. The occurrence of numerous aftershocks associated with a large intraslab earthquake provides such a rare opportunity. Based on the tomography method of Zhao et al. (1992, 1993), Mishra and Zhao (2004) determined the detailed seismic velocity structure in and around the hypocenter of the $2003 \mathrm{M}$ 7.1 Miyagi-Oki earthquake, which occurred at a depth of c. $70 \mathrm{~km}$ in the Pacific slab near the oceanic Moho beneath NE Japan. In their tomographic inversions, they used many data from aftershocks in addition to the background earthquake data, which enabled precise imaging of the source area within the slab. P-wave velocity structures revealed through this method are shown in 


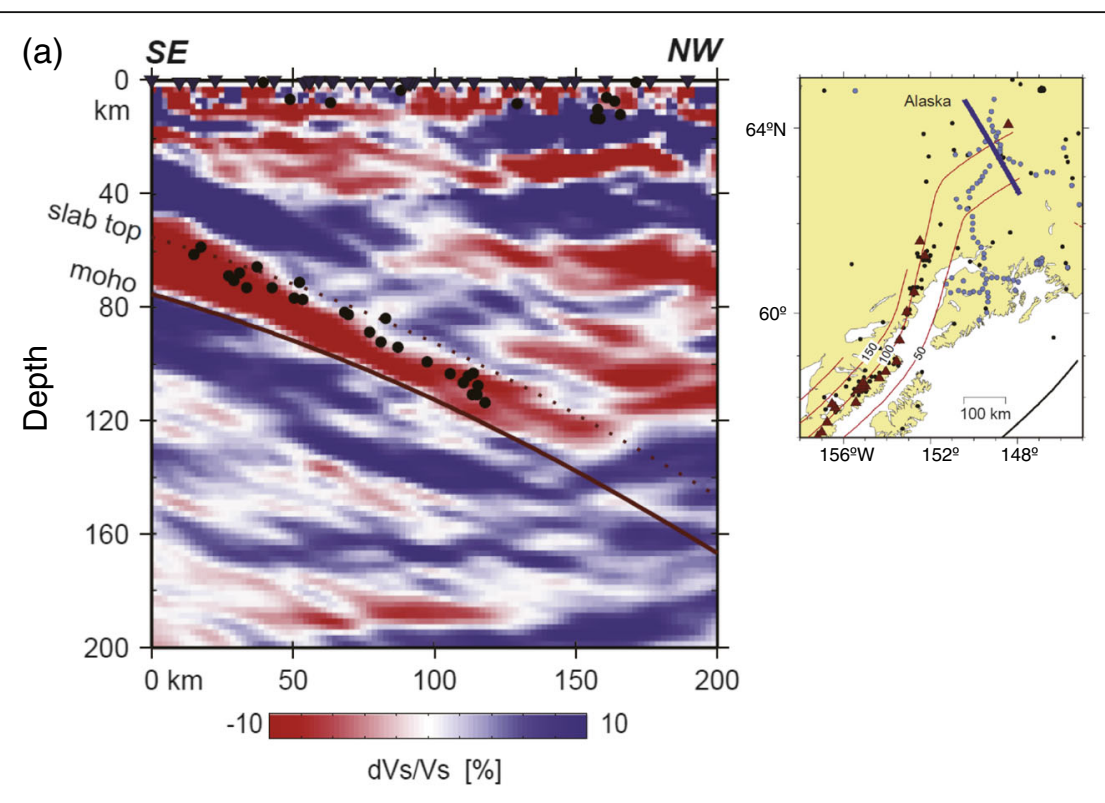

(b)
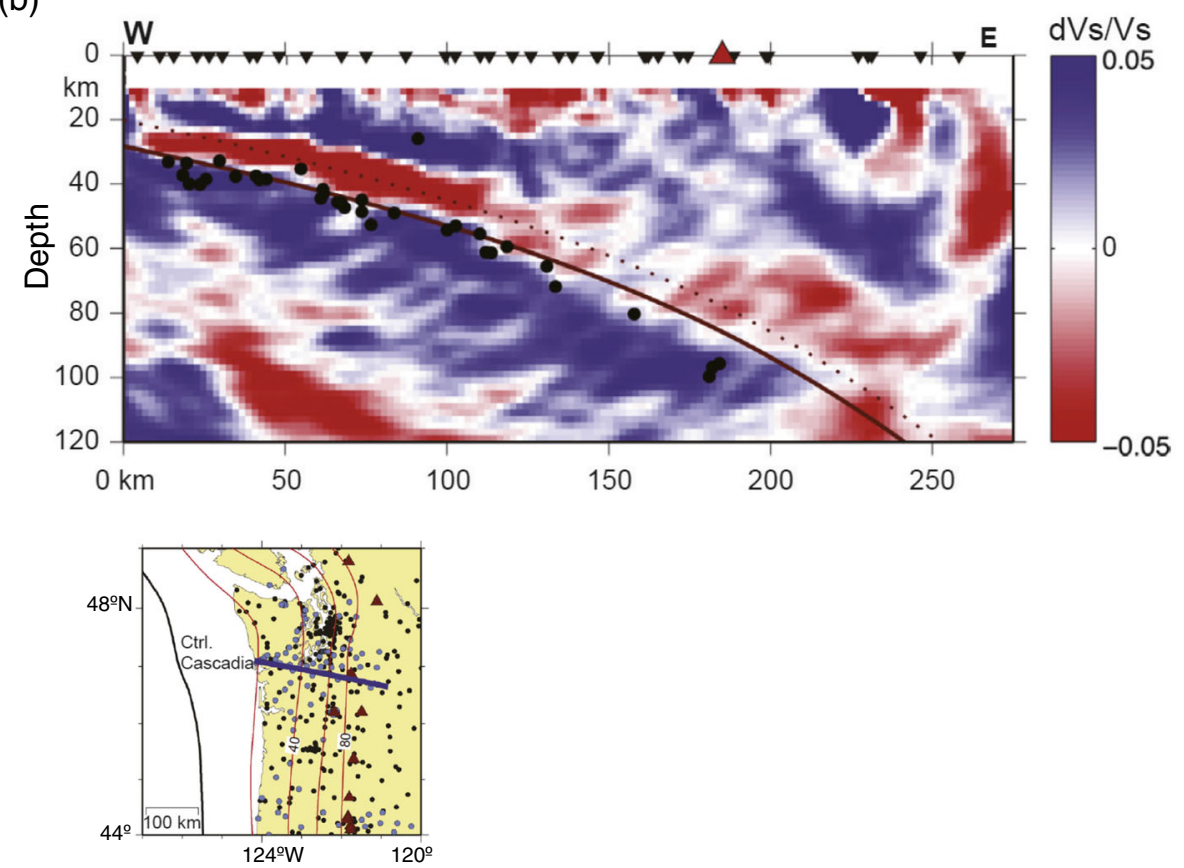

Fig. 16 S-wave velocity structures in central Alaska and central Cascadia. Across-arc seismic sections are shown along lines in the inset maps under a central Alaska and b central Cascadia (Abers et al. 2013, originally from Rondenay et al. 2008, 2010 and Abers et al. 2009). Colored images show migrated teleseismic $\mathrm{P}$ coda as dVs $\mathrm{Ns}$ (S-wave velocity perturbation). $\mathrm{dVs} / \mathrm{Ns}$ values are shown by the color scale at the bottom; red and blue correspond to slow and fast velocities, respectively. Black circles denote earthquakes. Dotted and solid lines indicate the upper slab surface and the slab Moho, respectively. Inverted black triangles show seismic stations used, and the red triangle in $\mathbf{b}$ shows a volcano

Fig. 17 in N-S and E-W vertical cross-sections that pass through the mainshock hypocenter. This figure shows an anomalously low-velocity zone across the crust and mantle in the Pacific slab and that the source area of the M 7.1 intermediate-depth intraslab event is located in this zone characterized by a velocity anomaly lower than its surroundings in the slab. Mishra and Zhao (2004) concluded that this low-velocity anomaly and the occurrence of earthquakes within it could be attributed to the process of fluid-related embrittlement caused by the dehydration of hydrous minerals in the slab.

Nakajima et al. (2011) examined the seismic wave velocity structure of the source area of the 2011 M 7.1 Miyagi-Oki earthquake that took place at a depth of $\mathrm{c}$. 

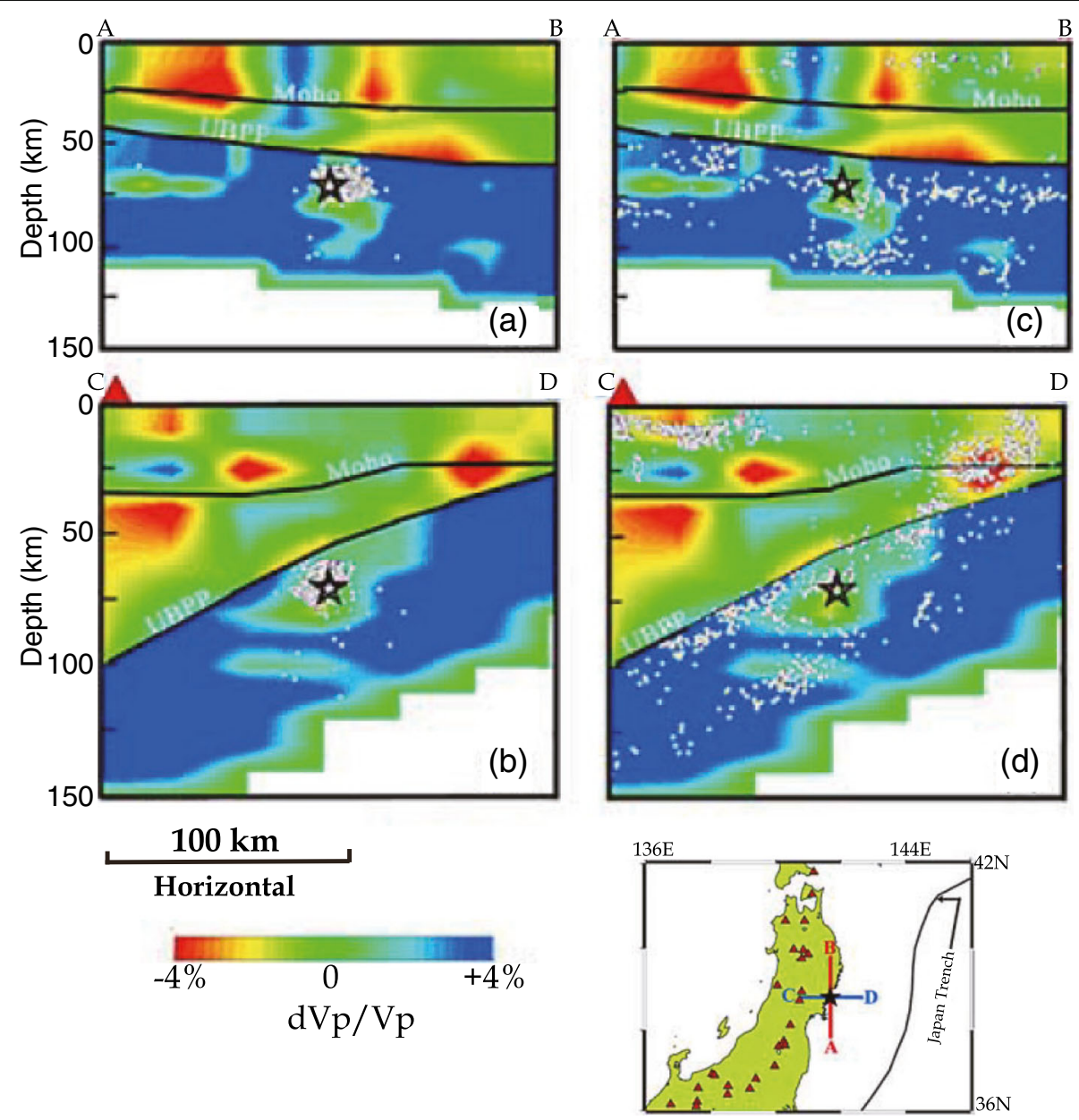

Fig. 17 P-wave velocity structure in and around the source area of the 2003 M 7.3 Miyagi-Oki intraslab earthquake. P-wave velocity perturbations are plotted based on the color scale at the bottom for $\mathbf{a}, \mathbf{c ~ N}-\mathrm{S}$ and $\mathbf{b}, \mathbf{d} \mathrm{E}-\mathrm{W}$ vertical cross-sections along lines shown in the inset map. White dots in $\mathbf{a}$ and $\mathbf{b}$ are aftershocks of the M 7.3 event, and those in $\mathbf{c}$ and $\mathbf{d}$ are background seismicity. Hypocenter of the M 7.3 event is indicated by a star. Thick curves are the Moho of the upper plate and the top surface of the subducting Pacific slab, in order from the top. (After Mishra and Zhao, 2004)

$65 \mathrm{~km}$ in the slab mantle about 1 month after the 2011 Mw 9.0 Tohoku-Oki earthquake. As shown in Fig. 18, the seismic wave velocity structure obtained by using numerous aftershock data in conjunction with the background seismicity data revealed the existence of a low-velocity zone around the fault plane of this M 7.1 intermediate-depth intraslab event. The lateral extent of the low-velocity zone is comparable to the extent of the fault plane of the M 7.1 event. The angle between the mainshock fault plane and the upper slab surface is c. $60^{\circ}$, which is consistent with the dip of the oceanwarddipping normal faults in the outer rise region. Based on these observations, Nakajima et al. (2011) suggested that the M 7.1 intraslab earthquake was generated by reactivation of a buried hydrated fault that had formed in the plate prior to its subduction.

Zhang et al. (2004) were the first to determine the detailed internal structure of the slab mantle to the depth of the lower seismic plane of the double seismic zone. Their tomographic imaging of the slab beneath central Tohoku with DD tomography revealed the existence of a P-wave low-velocity layer along the lower seismic plane, as shown in Fig. 19. The similar P-wave low-velocity layer along the lower seismic plane of the slab mantle was identified in subsequent seismic tomography studies by Shelly et al. (2006) and Nakajima et al. (2009c) under southern Tohoku and eastern Hokkaido, respectively. Figure 20 shows across-arc vertical cross-sections of $\mathrm{P}$ - and S-wave velocities under eastern Hokkaido as determined by Nakajima et al. (2009c). A clear P-wave low-velocity layer is visible at the lower plane of the double seismic zone. However, both Figs. 19 and 20 indicate that $\mathrm{S}$-wave velocity is not necessarily low for that layer. Therefore, the $\mathrm{Vp} / \mathrm{Vs}$ ratio for this layer is not necessarily as high as is expected for the serpentinized mantle, but may be fairly low, as shown in Fig. 19c.

Reynard et al. (2010) investigated the cause of the low $\mathrm{Vp}$ and $\mathrm{Vp} / \mathrm{Vs}$ values imaged via seismic tomography for this layer of the mid-slab mantle below 

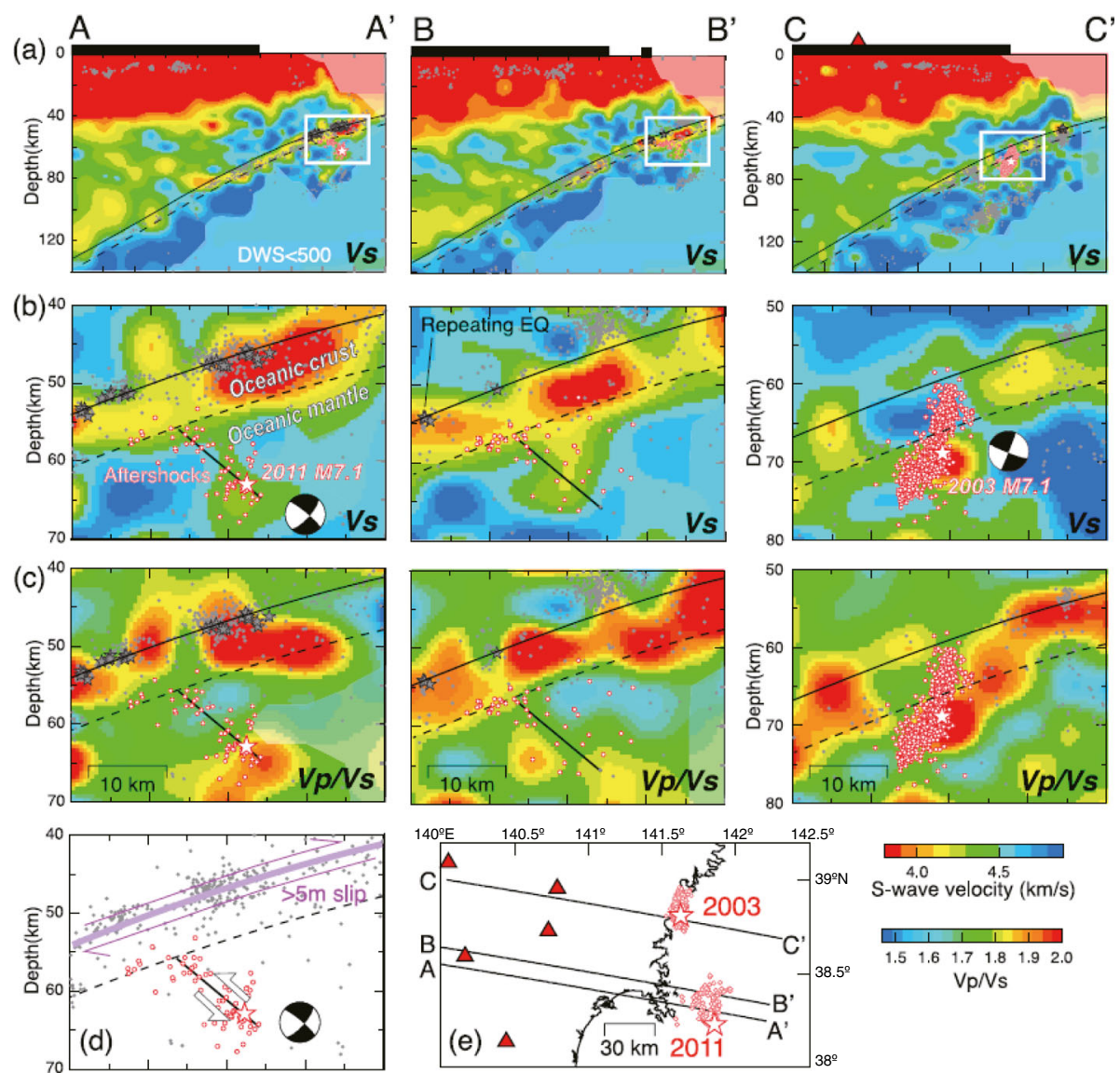

Fig. 18 Seismic velocity structure in and around the source area of the 2011 M 7.1 Miyagi-Oki intraslab earthquake. a Across-arc vertical crosssections of S-wave velocity under central Tohoku along three lines: $\mathbf{A}-\mathbf{A}^{\prime}, \mathbf{B}-\mathbf{B}^{\prime}$, and $\mathbf{C}-\mathbf{C}^{\prime}$ in the inset map e. White stars in line $\mathbf{A}-\mathbf{A}^{\prime}$ and line $\mathbf{C}-\mathbf{C}^{\prime}$ denote the hypocenter of the 2011 M 7.1 event and the 2003 M 7.1 event, respectively. Solid and dashed black curves denote the upper surface of the Pacific slab and the Moho within it, respectively. White rectangle in $\mathbf{a}$ shows the area enlarged in $\mathbf{b}$ and $\mathbf{c}$. $\mathbf{b}$ Across-arc vertical cross-sections of Swave velocity and $\mathbf{c} \vee p / N$ s within the area outlined by the white rectangle in $\mathbf{a}$. Black lines in $\mathbf{A}-\mathbf{A}^{\prime}$ and in $\mathbf{B}-\mathbf{B}^{\prime}$ show the fault plane of the 2011 M 7.1 event. d Schematic figure showing fault slips of the 2011 M 9.0 Tohoku-Oki earthquake (purple arrows) and the M 7.1 intraslab event (white arrows). e Map showing the aftershock distribution of the 2011 and 2003 intraslab events and the locations of the three lines, $\mathbf{A}-\mathbf{A}^{\prime}, \mathbf{B}^{-} \mathbf{B}$ ', and $\mathbf{C}-\mathbf{C}^{\prime}$. (After Nakajima et al. 2011)

eastern Hokkaido (Fig. 20). They claimed that this anomalous layer is the result of the anisotropy of anhydrous peridotite, which suggests that the same mineralogical composition occurs along the lower-plane seismicity as in the surrounding slab mantle. Based on this interpretation, they further argued that the shear heating instability of plastic deformation (Griggs and Handin, 1960; Ogawa, 1987; Hobbs and Ord, 1988) would therefore be the mechanism behind the lowerplane earthquakes. Conventionally, the thermal shear instability model was thought to be unable to explain the observation that the lower plane of the double seismic zone formed along the isotherm of approximately $600-700{ }^{\circ} \mathrm{C}$ in the slab mantle (see Figs. 5 and 6; Yamasaki and Seno, 2003;. Brudzinski et al. 2007). However, a recent investigation by Kelemen and Hirth (2007) based on numerical modeling of a fine-grained viscous shear zone in a coarse-grained elastic half-space revealed that the shear heating instability of peridotite occurs effectively within a narrow temperature range of $650-800{ }^{\circ} \mathrm{C}$. If this is the case, the shear heating instability model of plastic deformation can also explain the observations that the lower-plane events occur along the isotherm of approximately $600-700{ }^{\circ} \mathrm{C}$.

However, if we inspect the seismic tomography images (Fig. 20) of Nakajima et al. (2009c) in detail, regions with P-wave velocity below $7 \mathrm{~km} / \mathrm{s}$ are distributed entirely along the lower plane of the double seismic zone. It is difficult to explain the distribution of this low P-wave velocity anomaly along the lower seismic plane, but not in the surrounding mantle, based on the anisotropy of anhydrous peridotite alone. The low $\mathrm{Vp}$ values over the entire lower seismic plane imaged with seismic tomography suggest that materials with lower $\mathrm{Vp}$ were more 

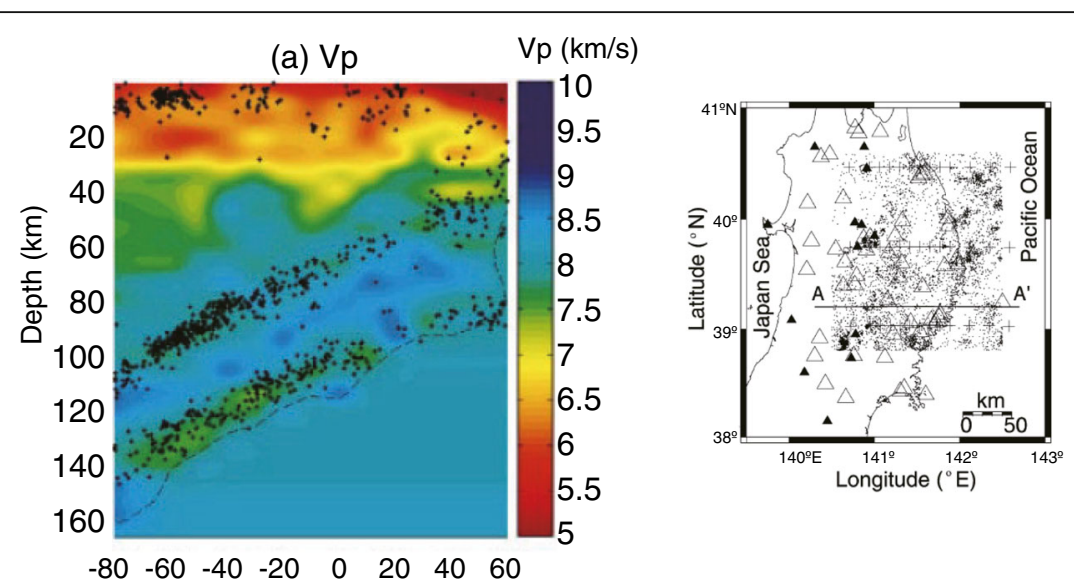

(b) Vs

Vs $(\mathrm{km} / \mathrm{s})$

(c) $\mathrm{Vp} / \mathrm{Vs}$
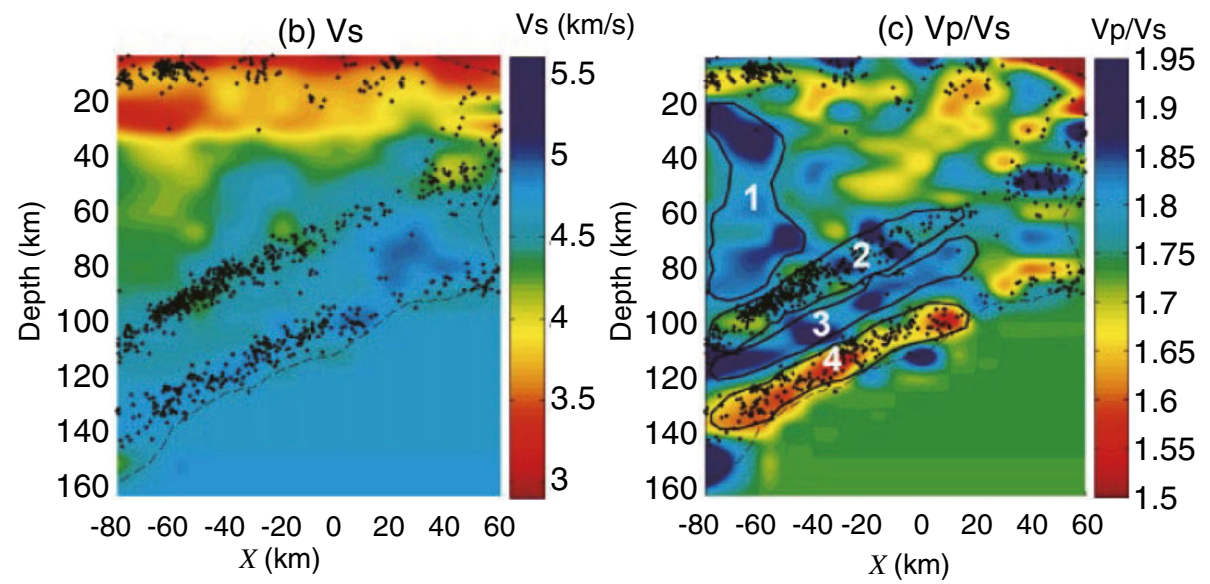

Fig. 19 Seismic velocity structure along the lower seismic plane under central Tohoku. Shown are across-arc vertical cross-sections of a P-wave velocity (Vp), b S-wave velocity (Vs), and $\mathbf{c} V p /$ s ratio under central Tohoku. P-wave velocity, S-wave velocity, and Vp/Vs ratio along the line in the inset map are shown by the color scale at the right of each figure. Black dots are earthquakes. (After Zhang et al. 2004)

abundant there than in the surrounding slab mantle, although the anisotropy effect of those materials may contribute in part to the lower $\mathrm{Vp}$ and $\mathrm{Vp} / \mathrm{Vs}$ values detected via seismic tomography. The low $\mathrm{Vp}$ and $\mathrm{Vp} / \mathrm{Vs}$ layer observed along the lower seismic plane is still not fully explained, and further examination and verification are required to determine the cause. Moreover, seismicity in the slab mantle is limited not only in the upper and lower planes of the double seismic zone but also between these planes, although the amount of seismic activity is lower (Kita et al. 2010b). Such interplane events are also shown in Fig. 20. In particular, the aftershock activity associated with the 1993 M 7.5 Kushiro-Oki earthquake at a depth of c. $100 \mathrm{~km}$ was distributed along a distinct P-wave low-velocity layer that extended horizontally from the lower seismic plane to the vicinity of the upper seismic plane (black arrow in Fig. 20c). This low P-wave velocity is also difficult to explain through the mechanism of peridotite anisotropy alone. The presence of interplane events (Kita et al. 2010b) indicates that intermediate-depth intraslab events occur even at temperatures much lower than $650-800{ }^{\circ} \mathrm{C}$, which further contradicts predictions based on the estimate of Kelemen and Hirth (2007).

Similar P-wave low-velocity layers along the lower plane of the double seismic zone were detected beneath northern Chile using DD tomography (Dorbath et al. 2008), although these results were less clear than those for beneath Tohoku and Hokkaido (Zhang et al. 2004; Shelly et al. 2006; Nakajima et al. 2009c). Across-arc vertical cross-sections of the estimated P- and S-wave velocities are shown in Fig. 21. This figure shows the presence of P-wave low-velocity zones along the lower seismic plane in all three cross-sections. As in the Pacific slab below eastern Japan, S-wave velocities are not low, but normal along the lower plane, which suggests that the low P-wave velocity and normal S-wave velocity along the lower seismic plane is a common feature across subduction zones. Dorbath et al. (2008) inferred that these P-wave low-velocity zones form along the slab's flexural neutral plane where fluids released through dehydration of the surrounding hydrated minerals accumulate. Therefore, the $\mathrm{P}$-wave velocities are low and trigger lower-plane seismicity. 


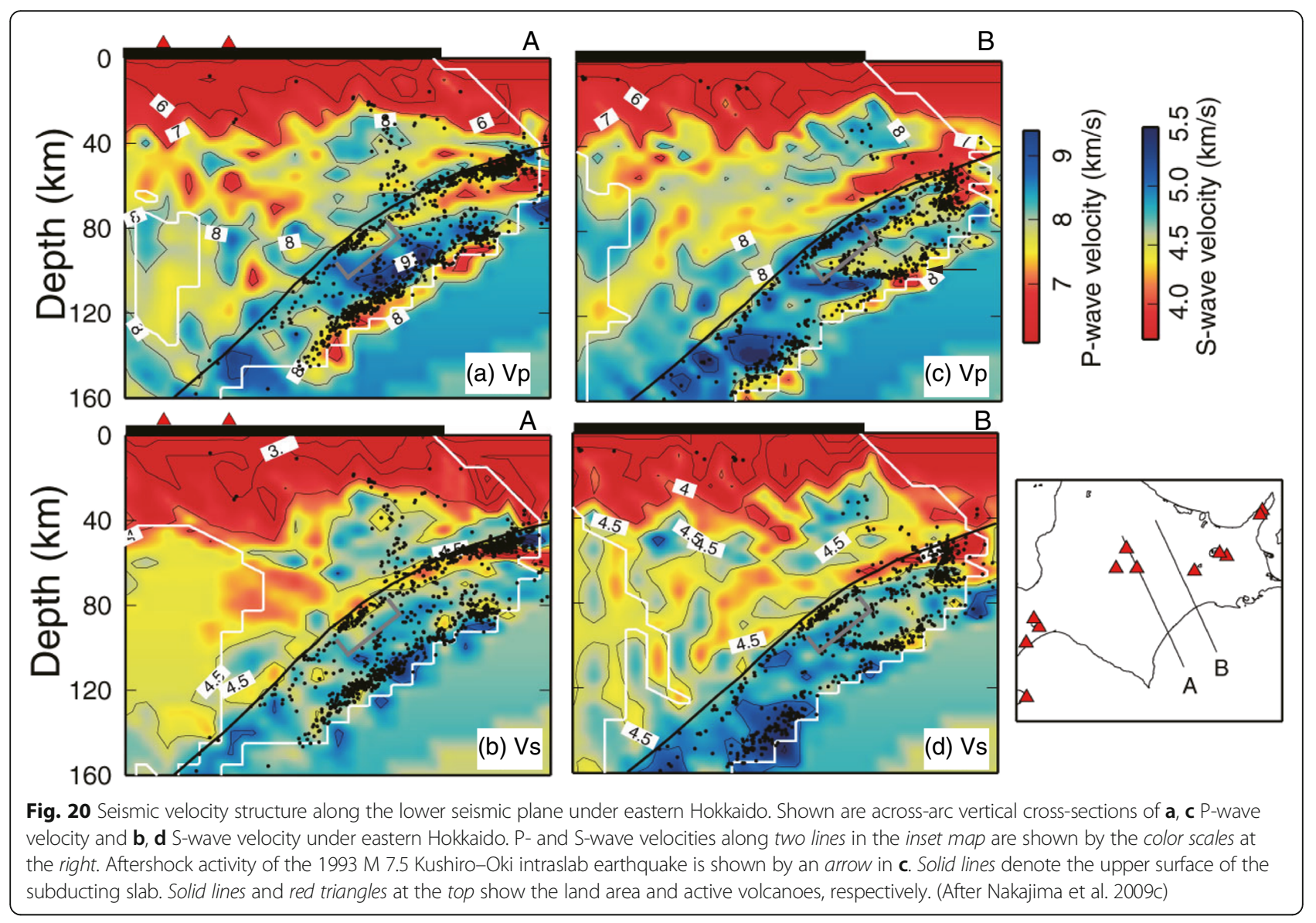

For lower-plane events to be triggered by the aqueous fluids liberated from hydrous minerals via dehydration reactions, at least part of the slab mantle near the lower plane must be hydrated. However, the lower seismic plane is usually located at depths of several tens of kilometers, to as deep as c. $40 \mathrm{~km}$, below the upper slab surface. In contrast, hydrothermal circulation and alteration at mid-ocean ridges are limited in many cases to shallow crustal levels. Peacock (2001) suggested that normal faulting in the trench-outer rise regions promotes infiltration of seawater several tens of kilometers into the oceanic plate, which facilitates the serpentinization of affected mantle materials. However, this hypothesis of the deep hydration of the oceanic mantle before the plate subduction has received criticism, and it is still controversial whether seawater infiltration extends to such great depths through bending-related normal faulting.

Seismic reflection/refraction surveys conducted at trench-outer rise regions have revealed the presence of such normal faults that cut across the crust and penetrate into the mantle of the incoming oceanic plate (e.g., Ranero et al. 2003; Ranero and Sallares, 2004). Seismic reflection/refraction profiling experiments have provided further evidence of alteration of the crust and mantle of the incoming plate: anomalously low seismic wave velocities in the crust and mantle (Ivandic et al. 2008; Grevemeyer et al. 2007; Contreras-Reyes et al. 2007, 2011; Fujie et al. 2013). Seismic surveys have thus detected traces of the altered crust and mantle of the incoming oceanic plate, but these surveys are restricted to the uppermost mantle levels, with a maximum depth of c. $20 \mathrm{~km}$. However, this limitation is mainly related to poor resolution at such great depths in the mid-mantle of oceanic plates associated with seismic surveys. In fact, a recent seismic reflection survey along a $233 \mathrm{~km}$-long profile beneath the Wharton Basin in the Indian Ocean clearly imaged a fault that extends down to $40 \mathrm{~km}$ depth below the plate upper surface (Qin and Singh, 2015). The negative polarity of the reflection indicates the presence of a low P-wave velocity zone along the fault, likely formed by serpentinization of mantle materials caused by infiltration of seawater. Although it is unclear whether the fault was formed by the bending stresses of the trench-outer rise region, this observation suggests the possibility of deep hydration of the oceanic mantle prior to plate subduction. Moreover, an estimation by Garth and Rietbrock (2014) based on waveform modeling of $\mathrm{P}$-wave coda from intermediate-depth 


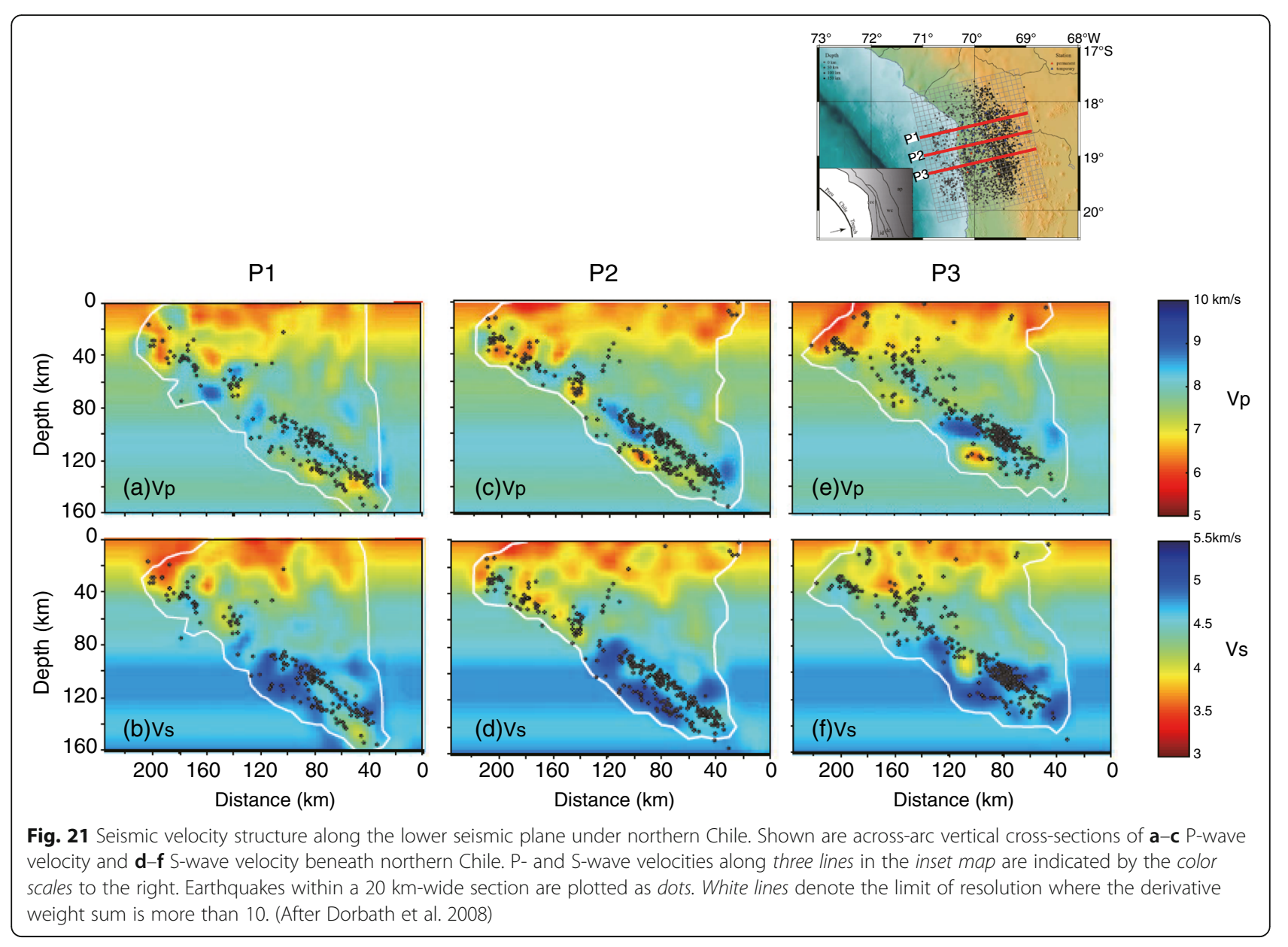

events, whereby a $40 \mathrm{~km}$-thick layer is inferred to be $17-31 \%$ serpentinized, indicates bulk hydration of the oceanic mantle.

A possible alternative mechanism for hydration of the deep mantle of an incoming oceanic plate is the hypothesis proposed by Seno and Yamanaka (1996). These workers discussed the possibility of hydration of the middle-to-deep portion of the oceanic plate through $\mathrm{H}_{2} \mathrm{O}$ released from solidified magma that was involved in plumes. Most of the magma solidifies and releases $\mathrm{H}_{2} \mathrm{O}$ at the plume head immediately below the oceanic plate; this $\mathrm{H}_{2} \mathrm{O}$ then accretes to the plate as the plate cools and thickens. In addition, magma injected into the oceanic plate releases $\mathrm{H}_{2} \mathrm{O}$ as it solidifies. $\mathrm{H}_{2} \mathrm{O}$ thus released reacts with the surrounding mantle materials, which results in the hydration of the mid-mantle. There are arguments against this hypothesis, as well; for example, Omori et al. (2009) argued that extensive hydration of the lithospheric mantle would not result from such a mechanism because the amount of $\mathrm{H}_{2} \mathrm{O}$ released decreases at greater depths due to depthbased variation in the solubility of $\mathrm{H}_{2} \mathrm{O}$ in the melt, and because magma reservoirs are present at shallow depths in the crust rather than such great depths in the mantle.
A dynamic thermomechanical-petrological modeling study of plate subduction by Faccenda et al. (2012) has presented another possibility for the penetration of $\mathrm{H}_{2} \mathrm{O}$ into the deep slab mantle. The results of their simulation show that during slab subduction, fluids liberated through dehydration of hydrous minerals follow a bimodal migration pattern. Fluids released from the slab crust and the sub-Moho mantle flow upward, whereas those released from deeper levels of the mantle are driven into the cold core of the slab because of the pressure gradients generated by plate unbending stresses. Fluids thus driven downward into the cold core of the slab accumulate progressively and percolate updip along a layer nearly parallel to the slab surface (Fig. 22). The predicted location of this layer of accumulated fluids coincides with the lower plane of the double seismic zone. This lower layer moves deeper with increasing plate age, and the separation distance between this lower layer and the middle of the slab crust is roughly consistent with the separation of double seismic zones observed globally by Brudzinski et al. (2007), as shown in Fig. 23. Both free fluids and serpentinized peridotite are present in this lower layer in the middle of the slab mantle because the mantle rocks there 


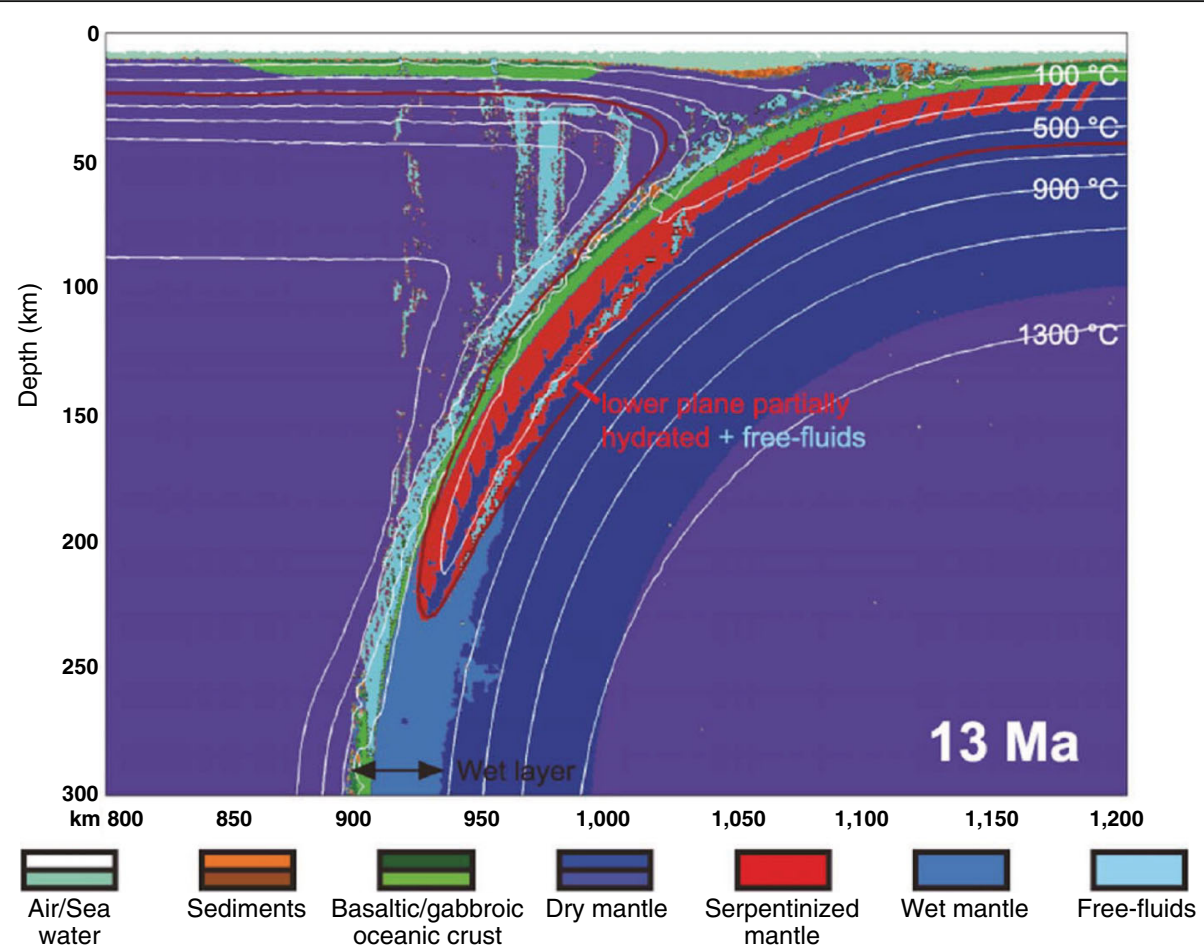

Fig. 22 Simulated hydration and dehydration of the subducting slab. Shown is an example of simulation results of a dynamic thermomechanicalpetrological model that shows the hydration and dehydration of the slab caused by its subduction and bending/unbending stresses. A snapshot of the hydration and dehydration at $13 \mathrm{Ma}$ after subduction is shown on an across-arc vertical cross-section of the case in which an oceanic plate with an age of $52 \mathrm{Ma}$ is subducting. White lines are isotherms. (After Faccenda et al. 2012)

are saturated with bound $\mathrm{H}_{2} \mathrm{O}$ to the assumed upper limit of serpentinization. If this assumption is accurate and the slab dip is not sufficiently shallow, extremely deep hydration of the slab mantle prior to subduction is unnecessary to explain the lower-plane seismicity. Moreover, if the free fluids are intensively distributed along the lower seismic plane as demonstrated here and if the pores that hold these fluids have small aspect ratios, the lower seismic plane should have low Vp and low Vp/Vs values (e.g., Nakajima et al. 2001; Takei, 2002). As suggested by Dorbath et al. (2008), this possibility may partially explain the low $\mathrm{Vp}$ and low $\mathrm{Vp} / \mathrm{Vs}$ along the lower plane, as is commonly observed in Tohoku, Hokkaido, and northern Chile (Figs. 19, 20, and 21).

The possibility of deep hydration of the slab mantle prior to subduction was also demonstrated by a recent 2$D$ reactive-flow model simulation of hydration processes at the trench-outer rise region (Iyer et al. 2012). Iyer et al. (2012) developed a reaction-transport model that enables better quantification of the amount and depth at which hydration occurs in an incoming oceanic plate due to normal faulting caused by the bending force. The hydration patterns determined with this model show the formation of a highly serpentinized band in the slab mantle centered at the $270{ }^{\circ} \mathrm{C}$ isotherm. The depth of the $270{ }^{\circ} \mathrm{C}$ isotherm increases with increasing plate age and is roughly consistent with the separation distance of globally observed double seismic zones (Fig. 6; Brudzinski et al. 2007). If this mechanism actually operates in the mantle, it could explain the formation of double seismic zones. Iyer et al. (2012) suggested that the double hydrated zone at the depths of the slab mantle, through slab unbending (Fig. 22; Faccenda et al. 2012) and maximum serpentinization at c. $270{ }^{\circ} \mathrm{C}$, may together cause the variations in the observed separation of the double seismic zone.

Recently, Korenaga (2017) demonstrated another possible mechanism for deep hydration of the slab mantle prior to subduction. He proposed that mantle hydration first occurs through thermal cracking associated with the cooling of oceanic plates and is later enhanced by bending-related faults in the outer rise region. The amount of fluids required to generate the lower plane of the double seismic zones is not well quantified, but Korenaga estimated the lower bound of the amount of water contained in the slab mantle (0.03-0.07 wt\%) and argued that this amount is sufficient to explain the lower-plane seismicity of double seismic zones.

Overall, observations of distinct low P-wave velocities along the lower plane of the double seismic zones under Tohoku, Hokkaido, and northern Chile, as shown in Figs. 19, 20, and 21, strongly suggest the presence of 


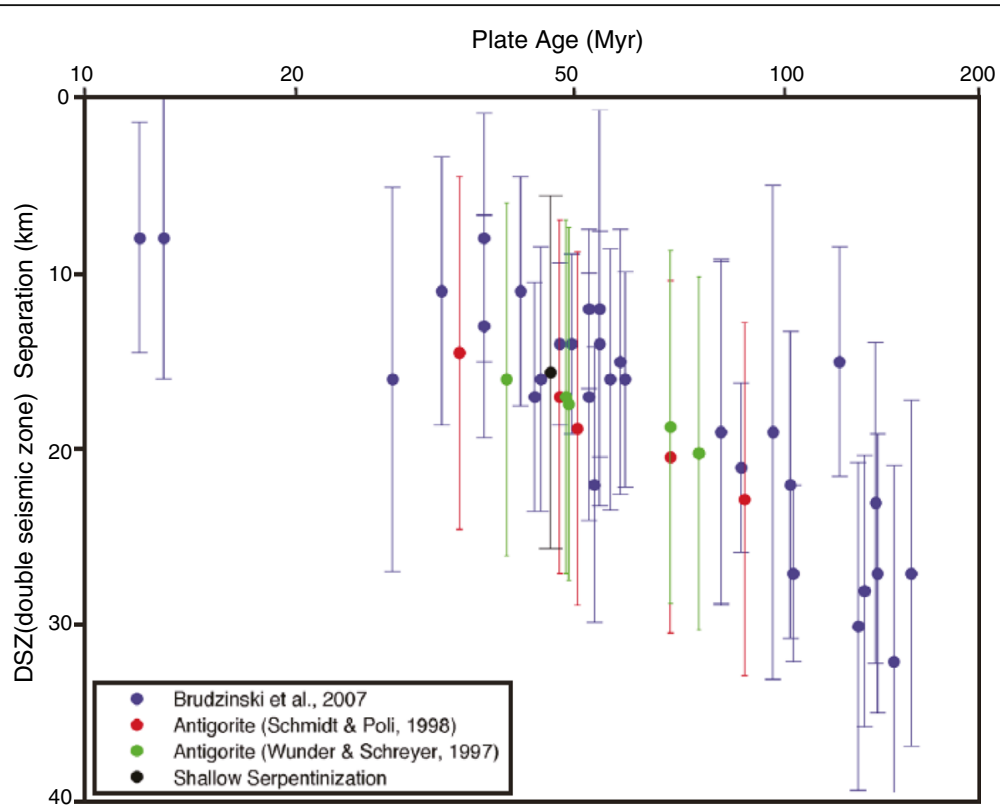

Fig. 23 Separation of the double seismic zone plotted against plate age. The separation of the double seismic zone obtained from a dynamic thermomechanical-petrological model is plotted against the age of the subducting slab. The distances from the middle of the oceanic crust to the level where fluids concentrate are shown by red and green dots. Vertical lines show error bars. Red and green dots are based on models of antigorite dehydration by Wunder and Schreyer (1997) and by Schmidt and Poli (1998), respectively. Blue dots are globally observed data reported by Brudzinski et al. (2007). (After Faccenda et al. 2012)

hydrous minerals or fluids in the middle portion of the slab mantle, although further investigation is necessary. We expect this research to progress in the future.

\section{Genesis of intermediate-depth intraslab earthquakes}

As described in the previous sections, spatial distribution of intraslab seismicity and the internal seismic structures of subducting slabs provide evidence that strongly supports the dehydration-related embrittlement hypothesis for nucleating intermediate-depth intraslab events. However, much of this evidence is circumstantial. The dehydration-related embrittlement hypothesis posits that $\mathrm{H}_{2} \mathrm{O}$ expelled from hydrous minerals within the subducting slab generates earthquakes, but the details of the process that actually lead from a state of local excess pore fluid pressure to earthquake rupture are still subject to debate (e.g., Raleigh and Paterson, 1965; Rutter and Brodie, 1988; Ko et al. 1997; Dobson et al. 2002; Jung and Green, 2004; Jung et al. 2004, 2006, 2009; Kelemen and Hirth, 2007; Chernak and Hirth, 2010, 2011; Brantut and Sulem, 2012; Sawai et al. 2013; Proctor and Hirth, 2015; Auzende et al. 2015).

Based on triaxial compression experiments on serpentinite samples at temperatures up to $700{ }^{\circ} \mathrm{C}$ and confining pressures up to $0.5 \mathrm{GPa}$ in undrained conditions, Raleigh and Paterson (1965) reported a significant reduction in strength of the samples, and brittle fracturing occurred at temperatures higher than $375{ }^{\circ} \mathrm{C}$, whereas plastic deformation occurred below $340{ }^{\circ} \mathrm{C}$. They attributed the embrittlement and weakening over $375^{\circ} \mathrm{C}$ to reduction in the effective normal stress caused by the release of the pore pressure of $\mathrm{H}_{2} \mathrm{O}$ via serpentine dehydration. This mechanism of dehydration embrittlement would certainly apply at pressures below c. $0.5 \mathrm{GPa}$ (corresponding to c. $15 \mathrm{~km}$ depth). However, it is not evident whether the same mechanism can be applied to intermediate-depth intraslab events that occur at much higher pressures. The effective stress law for sliding friction works at shallow depths, as seen in the experimental results of Raleigh and Paterson (1965), but this law does not work efficiently below the brittle-ductile transition depth (c. $15 \mathrm{~km}$ depth) (e.g., Hirth and Beeler, 2015). Another point, which is favorable to the dehydration-related embrittlement, in the experiments of Raleigh and Paterson (1965) is the positive Clapeyron slope of serpentine dehydration. The positive overall volume change associated with the dehydration in this case leads to an increase in pore pressure, which should operate to promote brittle fracture. However, at pressures higher than c. $2.2 \mathrm{GPa}$ (which corresponds to c. $60 \mathrm{~km}$ depth), the Clapeyron slope of serpentine dehydration is negative (see Fig. 3b), and thus, the overall volume change that accompanies the dehydration becomes negative, which may suppress the occurrence of brittle instability. 
In contrast, some laboratory experiments have shown that hydraulic embrittlement occurs even at this highpressure range. For example, Dobson et al. (2002) detected strong acoustic emission signals during dehydration in serpentinite compression experiments that used a multianvil press at pressures up to $8.5 \mathrm{GPa}$ and temperatures up to $900{ }^{\circ} \mathrm{C}$. Recovered samples show characteristics of the brittle deformation associated with high pore fluid pressures, which suggests that dehydration embrittlement occurs even at pressures over 2.2 GPa. Based on triaxial compression tests of antigorite at pressures up to $6 \mathrm{GPa}$ and temperatures up to $820{ }^{\circ} \mathrm{C}$, Jung et al. (2004) found that antigorite dehydration results in faults delineated by ultrafine-grained solid reaction products independent of the sign of the Clapeyron slope. Jung et al. (2009) conducted in situ measurements of acoustic emissions under compression tests of serpentinite and showed that acoustic waves are generated by dehydration embrittlement even at pressures higher than 2.2 GPa. These experimental results suggest that dehydration embrittlement is a viable mechanism for generating earthquakes independent of depth.

On the contrary, the results of some recent laboratory experiments do not support the dehydration embrittlement hypothesis. For example, Chernak and Hirth (2011) performed deformation experiments on antigorite designed to maximize the possibility of dehydration instability. They showed that unstable fault behavior did not develop in the specimens, but rather that slow slip events took place. Compression experiments of antigoriterich serpentinite by Gasc et al. (2011), who used a newly developed experimental setup that allows simultaneous collection of in situ X-ray diffraction data and recording of the full waveforms of acoustic emissions with a multianvil device, showed that the serpentinite samples did not produce detectable acoustic waves over the course of their dehydration. Proctor and Hirth (2015) conducted deformation tests with a new experimental method to vary the pore fluid pressure. Their results showed that dehydrating serpentinite causes deformation through semibrittle flow with grain-scale ductile deformation, which suggests that earthquakes do not nucleate due to unstable frictional sliding.

Triaxial compression tests on antigorite conducted recently by Okazaki and Hirth (2016) using a Griggs-type deformation apparatus showed that antigorite samples are associated with slow slips during the dehydration reaction without producing acoustic waves. Their similar deformation tests on lawsonite, however, showed that unstable fault slip certainly takes place and that acoustic emissions are continuously generated in the dehydration of lawsonite, which suggests that lawsonite dehydration may be the cause of intermediate-depth events in the subducting slab crust. These results support the hypothesis that embrittlement through blueschist-facies dehydration reactions in the slab crust may lead to the formation of the belt of upper-plane seismicity observed in the crust of the cold slabs, such as that detected under eastern Japan.

As described above, the detailed process that leads to earthquake rupture is still under debate, and is left to future works. However, because intermediate-depth earthquakes have been found to occur at the dehydration boundaries within the subducting slab as described in the previous sections, a process analogous to hydraulic fracturing may be occurring due to local excess pore fluid pressure formed through dehydration and expulsion of $\mathrm{H}_{2} \mathrm{O}$ from hydrous minerals. This phenomenon may cause intermediate-depth earthquakes within the slab. Alternatively, intermediate-depth events may be caused by dual mechanisms, both fluid-related embrittlement and thermal shear instability, i.e., the local excess pore fluid pressure may initiate earthquake rupture via hydraulic fracturing, which may then trigger subsequent earthquake ruptures through thermal shear instability. Nevertheless, it is estimated that $\mathrm{H}_{2} \mathrm{O}$ released by the dehydration of slab materials plays an important role in generating intermediate-depth intraslab earthquakes.

\section{Conclusions}

Intermediate-depth intraslab earthquakes occur within the existence range of hydrous minerals in the slab crust and slab mantle. In particular, intermediate-depth events tend to concentrate on the dehydration reaction boundaries in the slab, which forms the double seismic zone in the depth range of c. 40-180 km. Recent studies have revealed detailed spatial distribution of intermediatedepth seismicity that shows a close relationship with slab metamorphism. The pressure-temperature path of the crust for cold subducting slabs encounters facies boundaries with large rates of $\mathrm{H}_{2} \mathrm{O}$ production and positive total volume change, which are likely to promote the occurrence of earthquakes near the facies boundaries in the crust due to increase in pore fluid pressure. Conversely, the path for warm slabs encounters boundaries with slow $\mathrm{H}_{2} \mathrm{O}$ production rates and negative volumetric change, which may not effectively promote earthquake occurrence. Observations show that intermediate-depth earthquakes in warm slabs occur preferentially within the slab mantle or very close to the slab Moho, whereas those in cold slabs occur throughout the slab crust as well as in the slab mantle. Precise hypocenter locations of intermediate-depth events in NE Japan further demonstrate the presence of a belt of upper-plane seismicity in the crust of the cold Pacific slab that is nearly parallel to the 80-90 km depth contours of the upper slab surface. This concentration of seismic activity in the slab crust is probably caused by dehydration reactions with large $\mathrm{H}_{2} \mathrm{O}$ production rates and positive net volume 
change. A seismic low-velocity layer detected in the slab crust persists down to the depth of this upper-plane seismic belt, but no further, which provides evidence that the phase transformation of the dehydration reaction occurs there. Both the belt of the upper-plane seismicity and the down-dip end of the seismic low-velocity layer deepen locally under Kanto and SW Hokkaido, and these deepenings coincide spatially with the areas of contact with the overlying Philippine Sea slab and subducted forearc crust, respectively. This local deepening is probably caused by delay of the phase transformation of the slab crust because of the thermal shielding effect of the overlying cold bodies. Although the belt of the upper-plane seismicity was also detected in the cold Philippine Sea slab beneath southern Kyushu, it has not been detected in cold slabs of other subduction zones of the world. This absence of evidence may simply reflect the shortage of high-quality data for intermediate-depth events precisely located in those subduction zones. However, similar low-velocity subducting crust with a close relationship with intraslab seismicity has been detected in several other subduction zones. Anomalously, low P- and S-wave velocity zones have been detected in the source area of M7-class large, intraslab events that occurred in the slab crust and the uppermost portion of the slab mantle in NE Japan, which suggests the presence of hydrous minerals or fluids. The situation for lower-plane events is somewhat more complicated. Seismic tomography studies in both eastern Japan and northern Chile again revealed the presence of a P-wave low-velocity layer along the lower plane of the double seismic zone. This P-wave low-velocity layer is not associated with low $\mathrm{S}$-wave velocity, however, which is inconsistent with predictions based on the serpentinized mantle materials. Seismic anisotropy and pore aspect ratio may also play important roles in generating this unique structure. Although further validation is necessary for confirmation, the widespread distribution of a definite low-velocity P-wave layer along the entire lower seismic plane suggests the presence of hydrous minerals or fluids at that level, as well as the fluid-facilitated generation of lower-plane seismicity. All of these observations support the hypothesis that slab-derived $\mathrm{H}_{2} \mathrm{O}$ causes intermediate-depth intraslab earthquakes. However, the possibility has not been ruled out that $\mathrm{H}_{2} \mathrm{O}$ contributes only to earthquake nucleation and that seismic ruptures propagate through another mechanism. In other words, intermediate-depth events may be caused by both fluid-related embrittlement and thermal shear instability, i.e., local excess pore pressure may initiate earthquake rupture, and thus trigger subsequent earthquake ruptures through thermal shear instability. We anticipate significant progress in this area of research in the future to further verify this hypothesis for the genesis of intermediate-depth earthquakes, such as improving the accuracy of the temperature model, increasing the spatial resolution of seismic tomography imaging of the internal structures of subducting slabs, and deepening our understanding of the detailed processes that lead to earthquake rupture from a state of local excess pore fluid pressure based on rock deformation experiments or numerical simulations.

\section{Acknowledgements}

The authors thank T. Okada, N. Uchida, S. Kita, T. Matsuzawa, S. Kirby, S. Maruyama, and $\mathrm{S}$. Omori for valuable discussions. The authors also wish to thank the editor Fenglin Niu and two anonymous reviewers for their constructive comments, which greatly improved the manuscript.

\section{Funding}

Not applicable.

\section{Authors' contributions}

$\mathrm{AH}$ proposed the topic, wrote the manuscript, and prepared the figures. JN collaborated with the corresponding author in the construction of the manuscript and in the preparation of the figures. Both authors read and approved the final manuscript.

\section{Competing interests}

The authors declare that they have no competing interests.

\section{Publisher's Note}

Springer Nature remains neutral with regard to jurisdictional claims in published maps and institutional affiliations.

\section{Author details}

${ }^{1}$ Research Center for Prediction of Earthquakes and Volcanic Eruptions, Graduate School of Science, Tohoku University, Aramaki, Aoba-ku, Sendai 980-8578, Japan. ${ }^{2}$ Department of Earth and Planetary Sciences, School of Science, Tokyo Institute of Technology, 2-12-1 Ookayama, Meguro-ku, Tokyo 152-8551, Japan.

Received: 27 October 2016 Accepted: 22 March 2017 Published online: 10 April 2017

\section{References}

Abers GA (1992) Relationship between shallow- and intermediate-depth seismicity in the eastern Aleutian subduction zone. Geophys Res Lett 20: 2019-2022

Abers GA (1996) Plate structure and the origin of double seismic zones. In: Bebout GE, Scholl DW, Kirby SH, Platt JP (eds) Subduction, Top to Bottom, Geophys Mon 96. Amer Geophys Union, Washington, DC, pp 223-228

Abers GA (2000) Hydrated subducted crust at 100-250 km depth. Earth Planet Sci Lett 176:323-330

Abers GA (2005) Seismic low-velocity layer at the top of subducting slabs beneath volcanic arcs: observations, predictions, and systematic. Phys Earth Planet Int 149:7-29. doi:10.1016/jpepi200410002

Abers GA, MacKenzie LS, Rondenay S, Zhang Z, Wech AG, Creager KC (2009) Imaging the source region of Cascadia tremor and intermediate-depth earthquakes. Geology 37:1119-1122

Abers GA, Nakajima J, van Keken PE, Kita S, Hacker BR (2013) Thermal-petrological controls on the location of earthquakes within subducting plates. Earth Planet Sci Lett 369-370:178-187

Auzende AL, Escartin J, Walte NP, Guillot S, Hirth G, Frost DJ (2015) Deformation mechanisms of antigorite serpentinite at subduction zone conditions determined from experimentally and naturally deformed rocks. Earth Planet Sci Lett 411:229-240

Barcheck CG, Wiens DA, van Keken PE, Hacker BR (2012) The relationship of intermediate- and deep-focus seismicity to the hydration and dehydration of subducting slabs. Earth Planet Sci Lett 349-350:153-160

Bonatti E, Honnorez I (1976) Sections of the Earth's crust in the Equatorial Atlantic J Geophys Res 81:4104-4116 
Bostock MG, Hyndman RD, Rondenay S, Peacock SM (2002) An inverted continental Moho and serpentinization of the forearc mantle. Nature 417: 536-538. doi:10.1038/417536a

Brantut N, Sulem J (2012) Strain localization and slip instability in a strain-rate hardening, chemically weakening material. J Appl Mechan 79:031004-1-10

Brudzinski MR, Thurber CH, Hacker BR, Engdahl ER (2007) Global prevalence of double Benioff zones. Science 316:1472-1474

Burnley PC, Green HW, Prior DJ (1991) Faulting associated with the olivine to spinel transformation in $\mathrm{Mg}_{2} \mathrm{GeO}_{4}$ and its implications for deep focus earthquakes. J Geophys Res 96:425-443

Cassidy JF, Waldhauser F (2003) Evidence for both crustal and mantle earthquakes in the subducting Juan de Fuca plate. Geophys Res Lett 30:1095. doi:10.1029/ 2002GL015511

Chernak LC, Hirth G (2010) Deformation of antigorite serpentinite at high temperature and pressure. Earth Planet Sci Lett 296:23-33

Chernak LC, Hirth G (2011) Syndeformational antigorite dehydration produces stable fault slip. Geology 39:847-850. doi:10.1130/G319191

Comte D, Suarez G (1994) An inverted double seismic zone in Chile: evidence of phase transformation in the subducted slab. Science 263:212-215. doi:10. 1126/science 2635144212

Comte DL, Dorbath L, Pardo M, Monfret T, Haessler H, Rivera L, Frogneux M, Glass B, Meneses C (1999) A double-layered seismic zone in Arica, northern Chile. Geophys Res Lett 26:1965-1968. doi:10.1029/ 1999GL900447

Contreras-Reyes E, Grevemeyer I, Flueh ER, Reichert C (2007) Upper lithospheric structure of the subduction zone offshore of southern Arauco peninsula Chile, at 38º S. J Geophys Res 113:B07303. doi:10.1029/2007JB005569

Contreras-Reyes E, Grevemeyer I, Watts AB, Flueh ER, Peirce C, Moeller S, Papenberg C (2011) Deep seismic structure of the Tonga subduction zone: implications for mantle hydration, tectonic erosion, and arc magmatism. J Geophys Res 116:B10103. doi:10.1029/2011JB008434

Dixon JE, Leist L, Langmuir C, Schilling J (2002) Recycled dehydrated lithosphere observed in plume-influenced mid-ocean-ridge basalt. Nature 420:385-389

Dobson DP, Meredith PG, Boon SA (2002) Simulation of subduction zone seismicity by dehydration of serpentine. Science 298:1407-1410

Dorbath C, Gerbault M, Carlier G, Guiraud M (2008) Double seismic zone of the Nazca plate in northern Chile: high resolution velocity structure, petrological implications, and thermomechanical modeling. Geochem Geophys Geosyst 9:Q07006. doi:10.1029/2008GC002020

Eberhart-Phillips D, Bannister S (2015) 3-D imaging of the northern Hikurangi subduction zone, New Zealand: variations in subducted sediment, slab fluids and slow slip. Geophys J Int 201:838-855

Eberhart-Phillips D, Reyners M, Chadwick M, Chiu J-M (2005) Crustal heterogeneity and subduction processes: 3-D Vp, Vp/Ns and Q in the southern North Island, New Zealand. Geophys J Int 162:270-288

Engdahl ER, Villaseñor A (2002) Global Seismicity: 1900-1999. In: Lee WHK, Kanamori $H$, Jennings PC, Kisslinger C (eds) International handbook of earthquake and engineering seismology, Part A, Chapter 41. Amsterdam: Academic Press; pp 665-690

Engdahl ER, van der Hilst R, Bauland R (1998) Global teleseismic earthquake relocation with improved travel times and procedures for depth determination. Bull Seismol Soc Amer 88:722-743

Estabrook CH (1999) Body wave inversion of the 1970 and 1963 South American large deep-focus earthquakes. J Geophys Res 104:28751-28767. doi:10.1029/1999JB900244

Faccenda M (2014) Water in the slab: A trilogy. Tectonophysics 614:1-30. doi:10.1016/jtecto201312020

Faccenda M, Gerya TV, Burlini L (2009) Deep slab hydration induced by bendingrelated variations in tectonic pressure. Nat Geosci 2(11):790-793. doi:10. 1038/ngeo656

Faccenda M, Gerya TV, Mancktelow NS, Moresi L (2012) Fluid flow during slab unbending and dehydration: implications for intermediate-depth seismicity, slab weakening and deep water recycling. Geochem Geophys Geosyst 13: Q01010. doi:10.1029/2011GC003860

Frohlich C (1994) A break in the deep. Nature 368:101-101

Frohlich C (2006) Deep earthquakes. Cambridge University Press, New York

Fujie G, Kodaira S, Yamashita M, Sato T, Takahashi T, Takahashi N (2013) Systematic changes in the incoming plate structure at the Kuril trench. Geophys Res Lett 40:88-93. doi:10.1029/2012GL054340

Fukao Y, Hori S, Ukawa M (1983) A seismological constraint on the depth of the basalt-eclogite transition in a subducting oceanic crust. Nature 303:413-415
Garth T, Rietbrock A (2014) Order of magnitude increase in subducted $\mathrm{H}_{2} \mathrm{O}$ due to hydrated normal faults within the Wadati-Benioff zone. Geology 42:207-210. doi:10.1130/G347301

Gasc J, Schbnel A, Brunet F, Guillon S, Mueller H-J, Lathe C (2011) Simultaneous acoustic emissions monitoring and synchrotron $\mathrm{X}$-ray diffraction at high pressure and temperature: calibration and application to serpentinite dehydration. Phys Earth Planet Inter 189:121-133

Green HW, Burnley PC (1989) A new self-organizing mechanism for deep-focus earthquakes. Nature 341:733-737. doi:10.1038/341733a0

Green HW, Houston H (1995) The mechanics of deep earthquakes. Ann Rev Earth Planet Sci 23:169-213

Gregg PM, Lin J, Behn MD, Montesi LG (2007) Spreading rate dependence of gravity anomalies along oceanic transform faults. Nature 448:183-188

Grevemeyer I, Ranero CR, Flueh ER, Klaeschen D, Bialas J (2007) Passive and active seismological study of bending-related faulting and mantle serpentinization at the Middle America trench. Earth Planet Sci Lett 258:528-542. doi:10.1016/ jeps|200704013

Griggs DT, Handin J (1960) Observations on fracture and a hypothesis of earthquakes. In: Griggs DT, Handin J (eds) Rock deformation. J Geolog Soc Amer Memoir, vol 79., pp 347-373

Hacker BR (2008) H2O subduction beyond arcs. Geochem Geophys Geodyn 9: Q03001. doi:10.1029/2007GC001707

Hacker BR, Abers GA, Peacock SM (2003a) Subduction factory 1 theoretical mineralogy, densities, seismic wave speeds, and $\mathrm{H}_{2} \mathrm{O}$ contents. J Geophys Res 108(B1):2029. doi:10.1029/2001JB001127

Hacker BR, Peacock SM, Abers GA, Holloway SD (2003b) Subduction factory 2: are intermediate-depth earthquakes in subducting slabs linked to metamorphic dehydration reactions? J Geophys Res 108(B1):2030. doi:10.1029/2001JB001129

Hara T, Kuge K, Kawakatsu H (1996) Determination of the isotropic component of deep focus earthquakes by inversion of normal-mode data. Geophys J Int 127:515-528

Hasegawa A, Nakajima J (2004) Geophysical constraints on slab subduction and arc magmatism. In: The State of the Planet: Frontiers and Challenges in Geophysics, Geophys Monogr Ser 150. AGU, Washington, DC, pp 81-94

Hasegawa A, Umino N, Takagi A (1978a) Double-planed structure of the deep seismic zone in the northeastern Japan arc. Tectonophysics 47:43-58

Hasegawa A, Umino N, Takagi A (1978b) Double-planed deep seismic zone and upper-mantle structure in the northeastern Japan arc. Geophys J Int 54:281-296

Hasegawa A, Nakajima J, Kita S, Okada T, Matsuzawa T, Kirby S (2007) Anomalous deepening of a belt of intraslab earthquakes in the Pacific slab crust under Kanto, central Japan: possible anomalous thermal shielding, dehydration reactions, and seismicity caused by shallower cold slab material. Geophys Res Lett 34:L09305. doi:10.1029/2007GL029616

Hasegawa A, Nakajima J, Uchida N, Okada T, Zhao D, Matsuzawa T, Umino N (2009) Plate subduction, and generation of earthquakes and magmas in Japan as inferred from seismic observations: an overview. Gondwana Res 16:370-400

Hasegawa A, Nakajima J, Uchida N, Hirose F, Kita S, Matsuzawa T (2010) Slab structure beneath the Japanese Islands and earthquake generation. J Geogr 119:190-204 (in Japanese with English abstract)

Hasegawa A, Nakajima J, Zhao D (2016) Deep seismic structure. In: Geology of Japan. The Geological Society, London, pp 339-370

Helffrich GR (1996) Subducted lithospheric slab velocity structure: observations and mineralogical inferences. In: Bebout GE, Scholl D, Kirby SH, Platt JP (eds) Subduction top to bottom. Amer Geophys Union Geophys Mono, vol 96., pp 215-222

Hirose F, Nakajima J, Hasegawa A (2008a) Three-dimensional seismic velocity structure and configuration of the Philippine Sea slab in southwestern Japan estimated by double-difference tomography. J Geophys Res. 113. doi:10.1029/2007JB005274.

Hirose F, Nakajima J, Hasegawa A (2008a) Three-dimensional seismic velocity structure and configuration of the Philippine Sea slab beneath Kanto district, central Japan, estimated by double-difference tomography. J Seismol Soc Jpn 60:123-138 (in Japanese with English abstract)

Hirth G, Beeler NM (2015) The role of fluid pressure on frictional behavior at the base of the seismogenic zone. Geology 43:223-225

Hobbs BE, Ord A (1988) Plastic instabilities: implications for the origin of intermediate and deep focus earthquakes. J Geophys Res 93:10521-10540

Hori S (1990) Seismic waves guided by untransformed oceanic crust subducting into the mantle: the case of the Kanto district central Japan. Tectonophysics 176:355-376 
Hori S, Inoue H, Fukao Y, Ukawa M (1985) Seismic detection of the untransformed 'basaltic' oceanic crust subducting into the mantle. Geophys J Int 83:169-197

Houston H (2007) Deep earthquakes. In: Schubert G (ed) Treatise on Geophysics, vol 4, Earthquake Seismology. Elsevier, Amsterdam, pp 321-350

Igarashi T, Matsuzawa T, Umino N, Hasegawa A (2001) Spatial distribution of focal mechanisms for inter- and intraplate earthquakes associated with the subducting Pacific plate beneath the northeastern Japan arc: a triple-planed deep seismic zone. J Geophys Res 106:2177-2191

Ivandic M, Grevemeyer I, Berhorst A, Flueh ER, McIntosh K (2008) Impact of bending related faulting on the seismic properties of the incoming oceanic plate offshore of Nicaragua. J Geophys Res 113:B05410. doi:10.1029/2007JB005291

lyer K, Rüpke LH, Morgan JP, Grevemeyer I (2012) Controls of faulting and reaction kinetics on serpentinization and double Benioff zones. Geochem Geophys Geosyst 13:Q09010. doi:10.1029/2012GC004304

Jiao W, Silver PG, Fei Y, Prewitt CT (2000) Do intermediate- and deep-focus earthquakes occur on preexisting weak zones? An examination of the Tonga subduction zone. J Geophys Res 105:28125-28138

Jung H, Green HW (2004) Experimental faulting of serpentinite during dehydration: implications for earthquakes, seismic low-velocity zones, and anomalous hypocenter distributions in subduction zones. Int Geol Rev 46:1089-1102

Jung H, Green HW, Dobrzhinetskaya F (2004) Intermediate-depth earthquake faulting by dehydration embrittlement with negative volume change. Nature 428:545-549

Jung H, Fei YW, Silver PG, Green HW (2006) System for detecting acoustic emissions in multianvil experiments: application to deep seismicity in the Earth. Rev Sci Instrum 77:7

Jung H, Fei Y, Silver P, Green HW (2009) Frictional sliding in serpentine at very high pressure. Earth Planet Sci Lett 277:273-279. doi:10.1016/jeps|200810019

Kao H, Chen WP (1994) The double seismic zone in Kuril-Kamchatka: the tale of two overlapping single zones. J Geophys Res 99:6913-6930. doi:10.1029/ 92JB03409

Kao H, Rau RJ (1999) Detailed structures of the subducted Philippine Sea plate beneath northeast Taiwan: a new type of double seismic zone. J Geophys Res 104:1015-1033. doi:10.1029/1998JB900010

Karato S, Ridel MR, Yuen DA (2001) Rheological structure and deformation of subducted slabs in the mantle transition zone: implications for mantle circulation and deep earthquakes. Phys Earth Planet Inter 127:83-108

Kawakatsu H (1985) Double zone in Tonga. Nature 316:53-55. doi:10.1038/ $316053 \mathrm{a} 0$

Kawakatsu H (1986) Downdip tensional earthquakes beneath the Tonga arc: a double seismic zone? J Geophys Res 91:6432-6440

Kawakatsu H (1991) Insignificant isotropic component in the moment tensor of deep earthquakes. Nature 351:50-53. doi:10.1038/35100a0

Kawakatsu H (1996) Observability of the isotropic component of a moment tensor. Geophys J Int 126:525-544

Kelemen PB, Hirth G (2007) A periodic shear-heating mechanism for intermediatedepth earthquakes in the mantle. Nature 446:787-790. doi:10.1038/nature05717

Kimura G (1986) Oblique subduction and collision: forearc tectonics of the Kuril arc. Geology 14:404-407

Kirby SH (1987) Localize polymorphic phase transformations in high-pressure faults and applications to the physical mechanism of deep earthquakes. J Geophys Res 92:13789-13800

Kirby SH (1995) Intraslab earthquakes and phase changes in subducting lithosphere. US Ntl Rep Int Union Geod Geophys, 1991-1994. Rev Geophys 33:287-297

Kirby SH, Engdahl ER, Denlinger R (1996) Intermediate-depth intraslab earthquakes and arc volcanism as physical expressions of crustal and uppermost mantle metamorphism in subducting slabs. In: Bebout GE, Scholl D, Kirby SH, Platt JP (eds) Subduction, top to bottom. Geophys Mono Ser, 96. AGU, Washington, DC, pp 347-355

Kita S, Okada T, Nakajima J, Matsuzawa T, Hasegawa A (2006) Existence of a seismic belt in the upper plane of the double seismic zone extending in the along-arc direction at depths of 70-100 km beneath NE Japan. Geophys Res Lett 33: L24310. doi:10.1029/2006GL028239

Kita S, Okada T, Hasegawa A, Nakajima J, Matsuzawa T (2010a) Anomalous deepening of a seismic belt in the upper-plane of the double seismic zone in the Pacific slab beneath the Hokkaido corner: possible evidence for thermal shielding caused by subducted forearc crust materials. Earth Planet Sci Lett 290:415-426

Kita S, Okada T, Hasegawa A, Nakajima J, Matsuzawa T (2010b) Existence of interplane earthquakes and neutral stress boundary between the upper and lower planes of the double seismic zone beneath Tohoku and Hokkaido, northeastern Japan. Tectonophysics 496(1):68-82. doi:10.1016/jtecto201010010

Ko SC, Olgaard DL, Wong TF (1997) Generation and maintenance of pore pressure excess in a dehydrating system 1: experimental and microstructural observations. J Geophys Res 102:825-839

Kodaira S, Takahashi N, Park J, Mochizuki K, Shinohara M, Kimura S (2000) Western Nankai Trough seismogenic zone: results from a wide-angle ocean bottom seismic survey. J Geophys Res 105(B3):5887-5905

Kodaira S, lidake T, Kato A, Park J, Iwasaki T, Kaneda Y (2004) High pore fluid pressure may cause silent slip in the Nankai Trough. Science 304:1295-1298

Korenaga J (2017) On the extent of mantle hydration caused by plate bending. Earth Planet Sci Lett 457:1-9

Kuge K, Kawakatsu H (1993) Significance of non-double couple components of deep and intermediate-depth earthquakes: implications from moment tensor inversions of long-period seismic waves. Phys Earth Planet Inter 75:243-266

Leith A, Sharpe JA (1936) Deep-focus earthquakes and their geological significance. J Geol 44:877-917

Matsuzawa T, Umino N, Hasegawa A, Takagi A (1986) Upper mantle velocity structure estimated from PS-converted wave beneath the northeastern Japan arc. Geophys $J$ Int 86:767-787

Matsuzawa T, Kono T, Hasegawa A, Takagi A (1990) Subducting plate boundary beneath the northeastern Japan arc estimated from SP converted waves. Tectonophysics 181:123-133

Meade C, Jeanloz R (1991) Deep-focus earthquakes and recycling of water into the earth's mantle. Science 252:68-72

Mishra OP, Zhao D (2004) Seismic evidence for dehydration embrittlement of the subducting Pacific slab. Geophys Res Lett 31:L09610. doi:10.1029/2004GL019489

Nakajima J, Hasegawa A (2007) Tomographic evidence for the mantle upwelling beneath southwestern Japan and its implications for arc magmatism. Earth Planet Sci Lett 254:90-105

Nakajima J, Hasegawa A (2010) Cause of M7 earthquakes beneath the Tokyo metropolitan area, Japan: possible evidence for a vertical tear at the easternmost portion of the Philippine Sea slab. J Geophys Res. 115. doi:10. 1029/2009JB006863.

Nakajima J, Matsuzawa T, Hasegawa A, Zhao D (2001) Three-dimensional structure of $V p, V s$, and $V p /$ s beneath northeastern Japan: implications for arc magmatism and fluids. J Geophys Res 106(B10):21,843-21,858. doi:10.1029/2000JB000008

Nakajima J, Tsuji Y, Hasegawa A (2009a) Seismic evidence for thermally-controlled dehydration reaction in subducting oceanic crust. Geophys Res Lett 36: L03303. doi:10.1029/2008GL036865

Nakajima J, Hirose F, Hasegawa A (2009b) Seismotectonics beneath the Tokyo metropolitan area: effect of slab-slab contact and overlap on seismicity. J Geophys Res 114:B08309. doi:10.1029/2008JB006101

Nakajima J, Tsuji Y, Hasegawa A, Kita S, Okada T, Matsuzawa T (2009c) Tomographic imaging of hydrated crust and mantle in the subducting Pacific slab beneath Hokkaido, Japan: evidence for dehydration embrittlement as a cause of intraslab earthquakes. Gondwana Res 16:470-481

Nakajima J, Hasegawa A, Kita S (2011) Seismic evidence for reactivation of a buried hydrated fault in the Pacific slab by the 2011 M90 Tohoku Earthquake. Geophys Res Lett 38:L16318. doi:10.1029/2011GL048754

Nakajima J, Uchida N, Shiina T, Hasegawa A, Hacker BR, Kirby SH (2013) Intermediatedepth earthquakes facilitated by eclogitization-related stresses. Geology 41:659-662

Nishiyama T (1992) Mantle hydrology in a subduction zone: a key to episodic geologic events, double Wadati-Benioff zones and magma genesis. Math Seismol VII, R Inst Stat Math Tokyo 34:31-67

Ogawa M (1987) Shear instability in a viscoelastic material as the cause of deep focus earthquakes. J Geophys Res 92:13801-13810

Okal EA (1996) Radial modes from the great 1994 Bolivian earthquake: no evidence for anisotropic component to the source. Geophys Res Lett 23: 431-434. doi:10.1029/96GL00375

Okazaki K, Hirth G (2016) Dehydration of lawsonite could directly trigger earthquakes in subducting oceanic crust. Nature 530. doi:10.1038/nature16501.

Omori S, Kita S, Maruyama S, Santosh M (2009) Pressure-temperature conditions of ongoing regional metamorphism beneath the Japanese Islands. Gondwana Res 16:458-469

Peacock SM (2001) Are the lower planes of double seismic zones caused by serpentine dehydration in subducting oceanic mantle? Geology 29:299-302

Peacock SM, Wang K (1999) Seismic consequences of warm v. cool subduction metamorphism: examples from southwest and northeast Japan. Science 286:937-939 
Proctor B, Hirth G (2015) Role of pore fluid pressure on transient strength changes and fabric development during serpentine dehydration at mantle conditions: implications for subduction-zone seismicity. Earth Planet Sci Lett 421:1-12

Qin Y, Singh SC (2015) Seismic evidence of a two-layer lithospheric deformation in the Indian Ocean. Nat Commun 6:8298. doi:10.1038/ncomms9298

Raleigh CB (1967) Tectonic implications of serpentinite weakening. Geophys J Int $14: 113-118$

Raleigh CB, Paterson MS (1965) Experimental deformation of serpentinite and its tectonic implications. J Geophys Res 70:3965-3985

Ranero CR, Sallares V (2004) Geophysical evidence for alteration of the crust and mantle of the Nazca Plate during bending at the north Chile trench. Geology 32:549-552

Ranero CR, Morgan JP, Mclntosh K, Reicher C (2003) Bending-related faulting, and mantle serpentinization at the Middle America trench. Nature 425:367-373

Ranero CR, Villaseñor A, Morgan JP, Weinrebe W (2005) Relationship between bend-faulting at trenches and intermediate-depth seismicity. Geochem Geophys Geosyst 6:Q12002. doi:10.1029/2005GC000997

Reynard B, Nakajima J, Kawakatsu H (2010) Earthquakes and plastic deformation of anhydrous slab mantle in double Wadati-Benioff zones. Geophys Res Lett 37:L24309. doi:10.1029/2010GL045494

Reyners M, Robinson R, McGinity P (1997) Plate coupling in the northern South Island and southernmost North Island, New Zealand, as illuminated by earthquake focal mechanisms. J Geophys Res 102:15197-15210. doi:10.1029/ 97JB00973

Reyners M, Eberhart-Phillips D, Stuart G (1999) A three-dimensional image of shallow subduction: crustal structure of the Raukumara Peninsula, New Zealand. Geophys J Int 137:873-890

Rondenay S, Abers GA, van Keken PE (2008) Seismic imaging of subduction zone metamorphism. Geology 36:275-278

Rondenay S, Montési L, Abers GA (2010) New geophysical insight into the origin of the Denali volcanic gap. Geophys J Int 182:613-630

Rüpke LH, Morgan JP, Hort M, Connolly JAD (2004) Serpentine and the subduction zone water cycle. Earth Planet Sci Lett 223:17-34

Russakoff D, Ekstrom G, Tromp J (1997) A new analysis of the great 1970 Colombia earthquake and its isotropic component. J Geophys Res 102:20423-20434. doi:10.1029/97JB01645

Rutter EH, Brodie KH (1988) Experimental syntectonic dehydration of serpentinite under conditions of controlled pore water-pressure. J Geophys Res 93:4907-4932

Sawai M, Katayama I, Hamada A, Maeda M, Nakashima S (2013) Dehydration kinetics of antigorite using in situ high-temperature infrared microspectroscopy. Phys Chem Minerals 40:319-330. doi:10.1007/s00269-013-0573-9

Schmidt MW, Poli S (1998) Experimentally based water budgets for dehydrating slabs and consequences for arc magma generation. Earth Planet Sci Lett 163 361-379. doi:10.1016/S0012-821X(98)00142-3

Seno T, Maruyama S (1984) Paleogeographic reconstruction and origin of the Philippine Sea. Tectonophysics 102:53-84

Seno T, Yamanaka Y (1996) Double seismic zones, compressional deep trenchouter rise events and superplumes. In: Bebout GE, Scholl D, Kirby S, Platt JP (eds) Subduction: top to bottom, Geophys Mono Ser, 96. AGU, Washington, DC, pp 347-355

Shelly DR, Beroza GC, Zhang H, Thurber CH, Ide S (2006) High-resolution subduction zone seismicity and velocity structure beneath Ibaraki Prefecture, Japan. J Geophys Res 111:B06311. doi:10.1029/2005JB004081

Shiina T, Nakajima J, Matsuzawa T (2013) Seismic evidence for high pore pressure in the oceanic crust: implications for fluid-related embrittlement. Geophys Res Lett 40:2006-2010. doi:10.1002/grl50468

Smith SW, Knapp JS, McPherson RC (1993) Seismicity of the Gorda Plate, structure of the continental margin, and an eastward jump of Mendocino triple junction. J Geophys Res 98:8153-8171

Staudigel H, Davies GR, Hart SR, Marchant KM, Smith BM (1995) Large scale isotopic Sr, Nd and O isotopic anatomy of altered oceanic crust: DSDP/ODP sites 417/418. Earth Planet Sci Lett 130:105-120

Suzuki S, Sasatani T, Motoya Y (1983) Double seismic zone beneath the middle of Hokkaido, Japan, in the southwestern side of the Kurile Arc. Tectonophysics 96:59-76

Syracuse EM, Abers GA, Fischer K, MacKenzie L, Rychert C, Protti M, Gonza'lez V, Strauch W (2008) Seismic tomography and earthquake locations in the Nicaraguan and Costa Rican upper mantle. Geochem Geophys Geosyst 9: Q07S08. doi:10.1029/2008GC001963
Syracuse EM, van Keken PE, Abers GA (2010) The global range of subduction zone thermal models. Phys Earth Planet Inter 183:73-90. doi:10.1016/ jpepi201010021004

Takei Y (2002) Effect of pore geometry on Vp/Vs: from equilibrium geometry to crack. J Geophys Res 107(B2):2043. doi:10.1029/2001JB000522

Tsuji Y, Nakajima J, Hasegawa A (2008) Tomographic evidence for hydrated oceanic crust of the Pacific slab beneath northeastern Japan: implications for water transportation in subduction zones. Geophys Res Lett 35:L14308. doi:10.1029/2008GL034461

Tsumura K (1973) Microearthquake activity in the Kanto District. In: publications for the 50th anniversary of the Great Kanto Earthquake, 1923. Earthq Res Inst, Tokyo Univ. pp 67-87. (in Japanese)

Uchida N, Nakajima J, Hasegawa A, Matsuzawa T (2009) What controls interplate coupling?: Evidence for abrupt change in coupling across a border between two overlying plates in the NE Japan subduction zone. Earth Planet Sci Lett 283:111-121

Uchida N, Matsuzawa T, Nakajima J, Hasegawa A (2010) Subduction of a wedgeshaped Philippine Sea plate beneath Kanto, central Japan, estimated from converted waves and small repeating earthquakes. J Geophys Res 115. doi: 10.1029/2009JB006962.

Ulmer P, Trommsdorff V (1995) Serpentine stability to mantle depths and subductionrelated magmatism. Science 268:858-861

Umino N, Hasegawa A (1975) On the two-layered structure of deep seismic plane in northeastern Japan arc. J Seismol Soc Jpn 28:125-139 (in Japanese with English abstract)

van Keken PE, Kiefer B, Peacock S (2002) High-resolution models of subduction zones: implications for mineral dehydration reactions and the transport of water into the deep mantle. Geochem Geophys Geosyst 3(10):1056. doi:10. 1029/2001GC000256

Wada I, Wang K (2009) Common depth of slab-mantle decoupling: reconciling diversity and uniformity of subduction zones. Geochem Geophys Geosyst 10:Q10009

Wang K (2002) Unbending combined with dehydration embrittlement as a cause for double and triple seismic zones. Geophys Res Lett 29:1889. doi:10.1029/ 2002GL015441

Warren LM, Hughes AN, Silver PG (2007) Earthquake mechanics and deformation in the Tonga-Kermadec subduction zone from fault plane orientations of intermediate- and deep-focus earthquakes. J Geophys Res 112:B05314. doi:10.1029/2006JB004677.1

Warren LM, Langstaff MA, Silver PG (2008) Fault plane orientations of intermediatedepth earthquakes in the Middle America Trench. J Geophys Res 113:B01304. doi:10.1029/2007JB005028

Wunder B, Schreyer W (1997) Antigorite: high-pressure stability in the system $\mathrm{MgO}-\mathrm{SiO}_{2}-\mathrm{H}_{2} \mathrm{O}(\mathrm{MSH})$. Lithos 41:213-227

Yamasaki T, Seno T (2003) Double seismic zone and dehydration embrittlement of the subducting slab. J Geophys Res 108. doi:10.1029/2002JB001918.

Zhang $\mathrm{H}$, Thurber $\mathrm{CH}$ (2003) Double-difference tomography: the method and its application to the Hayward Fault, California. Bull Seismol Soc Amer 93:1875-1889

Zhang H, Thurber CH, Shelly D, Ide S, Beroza GC, Hasegawa A (2004) High-resolution subducting-slab structure beneath northern Honshu, Japan, revealed by doubledifference tomography. Geology 32:361-364

Zhao D, Hasegawa A (1993) P-wave tomographic imaging of the crust and upper mantle beneath the Japan Islands. J Geophys Res 98:4333-4353

Zhao D, Hasegawa A, Horiuchi S (1992) Tomographic imaging of P and S wave velocity structure beneath northeastern Japan. J Geophys Res 97:19909-19928

Zhao D, Matsuzawa T, Hasegawa A (1997) Morphology of the subducting slab boundary in the northeastern Japan arc. Phys Earth Planet Inter 102:89-104. doi:10.1016/S0031-9201(96)03258-X 